\title{
Integración regional por inversión extranjera directa del MERCOSUR y del TLCAN y el papel de sus socios menores, 1990-2016
}

\author{
Recibido: diciembre, 12 de 2018 - Aprobado: marzo, 21 de 2018
}

Doi: http://dx.doi.org/10.12804/revistas.urosario.edu.co/economia/a.8118

Nicolás Reig Lorenzi*

\section{Resumen}

Este artículo analiza y compara la integración por inversión extranjera directa del MERCOSUR y del TLCAN y el rol de Uruguay y México entre 1990-2016 con base en una nueva propuesta metodológica en el marco de las técnicas de análisis estructural. Los resultados sugieren que el MERCOSUR tuvo bajos niveles de integración aunque se incrementaron a lo largo del periodo, mientras que en el TLCAN la integración fue elevada, especialmente en algunos subperiodos. En este contexto, la integración de los socios menores tuvo grandes diferencias, siendo mucho más intensa en el caso de México que en el de Uruguay.

Palabras clave: integración regional, Inversión extranjera directa, MERCOSUR, TLCAN, socios menores

Clasificación JEL: F15, F21, F23.

* Departamento de Economía, Facultad de Ciencias Sociales, Universidad de la República, Uruguay. Constituyente 1502, 6º piso; Tel: (+598) 24106449 / interno 664; Fax: (+598) 24106450; Montevideo, Uruguay. Correo electrónico: nicolas.reig@cienciassociales. edu.uy. ORCID: http:/ / orcid.org/0000-0002-0572-3609. Agradezco los valiosos comentarios y sugerencias de Martín Puchet, y los comentarios y recomendaciones de los evaluadores anónimos.

Para citar este artículo: Reig Lorenzi, N. (2019). Integración regional por inversión extranjera directa del MERCOSUR y del TLCAN. Revista de Economía del Rosario 22(2), 187-229. Doi: http://dx.doi.org/10.12804/revistas.urosario.edu.co/economia/a.8118 


\title{
Regional Integration by Direct Foreign Investment of the MERCOSUR and NAFTA and the Role of its Smaller Partners, 1990-2016
}

\begin{abstract}
This paper analyzes and compares the integration by foreign direct investment (FDI) of MERCOSUR and NAFTA and the role of Uruguay and Mexico between 1990-2016 based on a new methodological proposal within the framework of structural analysis techniques. The results suggest that the Mercosur had low levels of integration although they increased throughout the period, while in NAFTA integration was high, especially in some subperiods. In this context, the coalition with the smaller partners had enormous differences, being much more intense in the case of Mexico than in the case of Uruguay.
\end{abstract}

Keywords: Regional integration, foreign direct investment, MERCOSUR, NAFTA, smaller partners

JEL Classification: F15, F21, F23.

\section{Integração regional por investimento estrangeiro direto do MERCOSUL e do NAFTA e o papel de seus sócios menores, 1990-2016}

\begin{abstract}
Resumo
Este artigo analisa e compara a integração por investimento estrangeiro direto do MERCOSUL e do NAFTA e o papel do Uruguai e do México entre 1990-2016 com base em uma nova proposta metodológica no marco das técnicas de análise estrutural. Os resultados sugerem que o MERCOSUL teve baixos níveis de integração ainda que se incrementaram ao longo do período, enquanto no NAFTA a integração foi elevada, especialmente em alguns subperíodos. Neste contexto, a integração dos sócios menores teve grandes diferenças, sendo muito mais intensa no caso do México que no caso do Uruguai.
\end{abstract}

Palavras-chave: integração regional, investimento estrangeiro direto, MERCOSUL, NAFTA, sócios menores.

Classificação JEL: F15, F21, F23. 


\section{Introducción}

A grandes rasgos, desde la década del noventa del siglo XX se producen significativos cambios en la economía internacional, con la profundización del proceso de globalización y el avance de la economía de mercado a nivel mundial. Una parte central de este proceso fue la intensificación del proceso de internacionalización productiva, mediante la enorme expansión de la presencia de empresas transnacionales (ET) en la economía mundial, a través de grandes corrientes de inversión extranjera directa (IED). En consecuencia, estos agentes pasaron a ocupar un rol central en la dinámica de la acumulación de capital así como en la organización de la producción y el comercio mundial, en particular por medio de la conformación de cadenas de valor regionales o mundiales $(\mathrm{CV}) .{ }^{1}$ Simultáneamente, se produce un fuerte crecimiento de las corrientes comerciales entre países y bloques de países, en buena medida debido a la proliferación de acuerdos comerciales bilaterales o multilaterales y a la conformación de acuerdos de integración regional, así como por los procesos de segmentación y deslocalización productiva que han liderado las ET dentro de las CV.

En este contexto mundial, desde principios de los noventa en muchos países de América Latina se implementaron profundas transformaciones en sus regímenes económicos, con la aplicación de reformas estructurales orientadas a una mayor apertura económica. Las reformas estuvieron inspiradas en el llamado "Consenso de Washington" y consistieron, en líneas muy generales, en la aplicación de un paquete de políticas económicas que buscaban promover el crecimiento y el desarrollo de los países mediante la apertura y la liberalización de las economías a las fuerzas del mercado. En la mayoría de los países se aplicaron medidas para profundizar la apertura y la liberalización comercial, en muchos casos en combinación con acuerdos de integración regional, por ejemplo el MERCOSUR, y se fueron liberalizando los regímenes de regulación de la IED junto a la aplicación de políticas específicas de promoción con el objetivo de captar mayores flujos de inversión externa (Chudnovsky \& López, 2006; Gallagher, López \& Porzecanski (eds.), 2008; Bittencourt, 2016). Como resultado, los países de la región profundizaron sus procesos de transnacionalización de sus economías, registrando un significativo ingreso de IED, tanto durante la década de los noventa como desde mediados de la década de los $2000 .^{2}$

1 Al respecto véase UNCTAD (2005), Chudnovsky y López (2006) y Bittencourt (coord.) (2012).

2 Al respecto véase, por ejemplo, Bittencourt (coord.) (2012) e informes de la CEPAL y UNCTAD. 
Dentro de los procesos de integración entre los países de las Américas se destaca la formación de los dos bloques más importantes del continente en términos económicos y comerciales: el MERCOSUR, en el año 1991, y del TLCAN, en 1994. Estos acuerdos de integración han involucrado países con características estructurales distintas y grandes diferencias o asimetrías económicas y sociales. El MERCOSUR está formado por un socio mayor, Brasil, un socio mediano, Argentina, y dos socios menores, Uruguay y Paraguay, mientras que el TLCAN tiene por socio mayor a EEUU, el socio mediano es Canadá y el socio relativamente menor es México. ${ }^{3}$ Además, el acuerdo de América del Sur involucra cuatro países en desarrollo, mientras que en América del Norte el bloque integra dos países desarrollados con uno en desarrollo.

El objetivo de este artículo es analizar y comparar los procesos de integración por IED de los dos grandes bloques de las Américas en el periodo 1990-2016, así como el rol de Uruguay en MERCOSUR y el de México en el TLCAN. En líneas generales, la integración por medio de flujos de IED se produce cuando empresas de un país del bloque invierten en otro país socio para establecer filiales productivas con el objetivo de desarrollar actividades en el mercado interno y/o para conformar redes productivas y de intercambio o cadenas de producción (regionales o globales), lo que implica en ambos casos, una mayor vinculación entre los países socios del acuerdo.

Es relevante señalar que desde 2004 existe un Tratado de Libre Comercio (TLC) entre Uruguay y México, que incluye un capítulo específico y diversas disposiciones respecto a la IED entre los países, lo cual constituye una excepción entre los países de los dos bloques, así como una relación y conexión particular entre los socios menores, aspectos que contribuyen a la opción de tomar en cuenta en el análisis a los dos países. Asimismo, la consideración de los socios menores de los dos acuerdos brinda la posibilidad de realizar un análisis comparativo sobre las trayectorias de estos países en el contexto de bloques con características diferentes.

Las preguntas que se busca responder son las siguientes: ¿cuál fue la evolución de la integración por IED en el MERCOSUR y en el TLCAN desde los años noventa hasta el presente?, ¿cuál fue el aporte de Uruguay y México en sus respectivos bloques? Las hipótesis centrales que se busca contrastar giran en torno a las siguientes proposiciones: 1) la integración regional por IED en el MERCOSUR fue baja mientras que la del TLCAN fue elevada y profundizó los vínculos entre los socios; 2) los socios relativamente meno-

3 Los países se clasifican principalmente por el tamaño de sus economías, en términos del PIB nominal, así como por otras variables relevantes, como se presenta en la sección 3. 
res tuvieron grandes diferencias en la integración por IED a sus respectivos acuerdos y, por lo tanto, el aporte fue mucho más importante en el caso de México que en el de Uruguay.

El análisis empírico de la integración regional a través de los flujos de IED se realiza mediante una nueva propuesta metodológica. La misma es una adaptación de la metodología de análisis de la integración comercial en base a matrices de intercambio bilateral y el cálculo de índices sistémicos de integración (ISIs) definidos por Prakas, Dietzenbacher y Basu (2007). En líneas generales, esta nueva metodología parte de la contabilización de todas las entradas y salidas de flujos de capital de los países de un acuerdo regional, a partir de los cuales se construyen matrices de flujos de fondos diferenciando los flujos emitidos y recibidos de IED a nivel intrarregional y extrarregional. En el marco de dichas matrices, es posible considerar modelos de entrada y salida por el lado de la oferta y demanda de fondos, en base a los cuales se calculan los ISIs por oferta (recepción) y demanda (emisión) de IED así como a nivel global (recepción y emisión).

Se considera que esta nueva propuesta metodológica es sumamente pertinente y relevante para el análisis del proceso de integración regional por medio de la IED, fundamentalmente porque permite cuantificar la interdependencia entre los países, considerando el bloque regional como un sistema. En este sentido, y de forma análoga a la integración comercial, los indicadores y medidas que se desprenden de la misma representan la intensidad y complejidad del acuerdo de integración en términos de la IED.

A su vez, el análisis de la integración se realiza desde el punto de vista macroeconómico y muestra el mayor o menor grado de integración por IED del bloque y los países a nivel agregado, el cual estará vinculado tanto a las tendencias subyacentes en la integración a nivel sectorial o meso económico, como a la relación que establecen las inversiones entre los países para desarrollar actividades en los mercados internos y/o para la formación de redes productivas y de intercambio en el marco de las cadenas de valor a nivel regional e internacional.

Interesa señalar que la metodología del análisis estructural de carácter macroeconómico que se aplica está enfocada en los encadenamientos producidos por las relaciones entre países vía IED y permite medir tanto la interdependencia entre los mismos como el papel de sus tamaños relativos. Al mismo tiempo, es el inicio requerido para articular, considerando la composición sectorial de las magnitudes totales, el nivel macro con el meso-económico, en la medida de que se disponga de matrices de flujos por bloque que estén clasificadas, de manera consistente, tanto entre países como intersectorialmente. Por lo tanto, este artículo se concentra en el estudio de la integración 
a nivel global, que brindará el marco general para profundizar en sucesivas investigaciones en el análisis sobre los tipos o formas de IED (por ejemplo horizontal o vertical) predominantes entre los países y a nivel del bloque.

Desde el punto de vista de los antecedentes empíricos, existe una amplia bibliografía que analiza los procesos de integración de cada uno de los bloques, en especial desde el punto de vista comercial e institucional. Sin embargo, la integración regional por medio de la IED recibida y emitida entre los socios de los respectivos acuerdos, que es otra dimensión sumamente relevante de la integración, ha sido poco analizada hasta el presente. En este caso, no hay trabajos que analicen la integración desde el punto de vista de la IED utilizando las metodologías de análisis estructural. Por lo tanto, este trabajo busca realizar aportes principalmente en dos direcciones: por un lado, mediante una nueva propuesta metodológica para analizar de manera específica la intensidad del proceso de integración por IED en bloques y países, y por otro, a través de la aplicación de esta metodología y la obtención de resultados empíricos para describir y analizar la evolución de este proceso en los dos grandes bloques de las Américas en los últimos 25 años y, en particular, respecto al papel de los socios relativamente menores de cada bloque.

La estructura del trabajo es la siguiente. Además de esta introducción, en la primera sección se resumen algunos aspectos teóricos sobre el rol de la IED en la integración regional. En la segunda, se presenta la descripción y análisis de las características generales de la integración por IED de cada bloque y en particular de los socios menores. En la tercera se expone la metodología y los indicadores. En la cuarta se muestran los resultados para los bloques y los países. Por último, en la última sección se presentan las principales conclusiones.

\section{Aspectos teóricos}

En esta sección se resumen algunos argumentos teóricos respecto a los impactos de los acuerdos de integración regional (AIR) sobre la IED, ${ }^{4}$ tanto a nivel intrarregional como extrarregional.

A grandes rasgos, "los vínculos entre los procesos de integración y la inversión extranjera directa son complejos y varían según la forma que adopte el marco regional" (Chudnovsky \& López (coord.), 2002). Como se señala en Bittencourt, Domingo y Reig (2006), los acuerdos de integración regional

4 Para una descripción y análisis en profundidad del concepto de IED y de Empresas Transnacionales (ET), según diferentes enfoques teóricos y analíticos, véase por ejemplo Trajtenberg (1999) y Chudnovsky (coord.) (2001). 
(AIR) pueden tener diferente impacto sobre los flujos de IED, el cual dependerá, entre otros, de los siguientes factores: las características de los países que se integran, la naturaleza del acuerdo de integración, el tipo de IED predominante en estos países (horizontal-vertical, orientada a la exportación o sustitutiva de importaciones), y las políticas adoptadas por los mismos antes y después del acuerdo. A su vez, este impacto puede ser distinto para los flujos intrarregionales y los extrarregionales.

Respecto a los flujos intrarregionales, puede existir un incremento de los mismos cuando la reducción de las barreras comerciales intrarregionales fomenta la IED vertical entre los socios, dado que las firmas distribuyen geográficamente su producción atendiendo a la búsqueda de menores costos totales y aumentan los flujos comerciales, siendo la IED y el comercio complementarios (Blomström \& Kokko, 1997; Marszk, 2014). A su vez, puede ocurrir una reducción de los flujos cuando las menores barreras comerciales intrarregionales generan un desplazamiento de IED horizontal por flujos de comercio, siendo la IED y el comercio sustitutos. En este caso, las firmas que previo al AIR atendían a un mercado a través de IED pueden pasar a hacerlo mediante exportaciones desde su país de origen una vez que el AIR está vigente (De Souza \& Lochard, 2004; Marszk, 2014).

En relación con los flujos extrarregionales, los AIR implican un incremento en el tamaño del mercado y pueden generar un aumento de la IED horizontal orientada al mercado, dependiendo de cuáles sean las barreras arancelarias de la región frente al resto del mundo. Si se trata de la IED vertical que implica fragmentación de la producción entre países miembros del AIR, es posible que el AIR tenga un impacto positivo en el ingreso de IED extrazona, mientras que si la IED vertical no implica fragmentación de la producción entre los países del acuerdo, ya que es probable que no exista un impacto positivo o tenga un impacto negativo si aumentan las barreras comerciales arancelarias con terceros países.

En este sentido, Markusen (2003) analiza, tomando como base su marco teórico, el efecto de los AIR sobre los flujos de IED extrazona diferenciando los AIR según tipos de países. En el caso de AIR entre países en desarrollo, al implicar un mercado de mayor tamaño relativo, podría fomentar el ingreso de IED horizontal de países extrazona. En el caso de que el AIR ocurra entre países desarrollados y países en desarrollo, también podrían aumentar los flujos de IED desde terceros países, en la medida que sus ET buscan explotar la oportunidad de ventajas de localización de los países en desarrollo para poder exportar a los países desarrollados que integran el acuerdo, siguiendo una forma de IED del tipo "plataforma de exportación". Esta estrategia también la utilizarían las ET de los países desarrollados que integran el acuerdo, 
aumentando los flujos de IED intrazona, generando un efecto de competencia sobre las ET de terceros países y debilitando los posibles beneficios de estas últimas.

En resumen, como señalan algunos autores, considerando los diversos efectos que pueden generarse a nivel intrarregional como extrarregional, el efecto de la integración regional sobre la IED es, a priori, ambiguo (Dunning \& Robson, 1987; Blomström \& Kokko, 1997, citados en Kreinin, M. \& Plummer, M., 2008). ${ }^{5}$

Otro aspecto relevante se refiere a la captación de flujos de IED por países integrantes de los AIR. Los mismos pueden presentar una distribución desigual, por lo que dentro de un acuerdo puede haber ganadores y perdedores en términos del monto de IED recibido por cada país. En la bibliografía sobre este tema particular, existe una discusión en torno a los distintos factores que podrían determinar si un país gana o pierde, entre ellos el tamaño del país, la calidad de sus instituciones, la calidad de su fuerza de trabajo, su régimen impositivo hacia las ET y el desarrollo de su infraestructura, etc. Sin embargo, este análisis generalmente está asociado con incrementos y reducciones de los flujos de IED, pero no considera otros aspectos relacionados con efectos de la IED sobre el bienestar de los países receptores, por ejemplo la discusión de los potenciales beneficios y costos de la IED que sugiere que no toda IED presenta beneficios similares, y tampoco se indica que países específicos, dentro de los diversos AIR, serían ganadores o perdedores(Bittencourt, Domingo \& Reig, 2006). ${ }^{6}$

\section{Integración, estructura de los bloques e IED}

En esta sección se presenta, por un lado, la evolución del proceso de integración en el MERCOSUR y el TLCAN y la estructura de cada bloque, y por otro, la evidencia empírica sobre la evolución de la IED en los países y bloques, en particular en Uruguay y México.

5 En este sentido, otros autores que también abordan esta problemática, por ejemplo desde la perspectiva del nuevo regionalismo y especialmente en sus aspectos analíticos, señalan que existen diferentes respuestas de la inversión al establecimiento y profundización de los acuerdos preferenciales de comercio. Al respecto véase, por ejemplo, Ethier (2001) y Dee y Gali (2005).

6 En general, se establecen un conjunto de características que posibilitarían que los diversos países se ubiquen en una u otra posición, siendo una visión estática de la relación IED-integración, en la medida que estos últimos pueden influir sobre la conformación del conjunto de características de los países miembros que los habilite a transitar de una posición relativa a otra. 


\subsection{El MERCOSUR y el TLCAN}

El MERCOSUR fue constituido a principios de la década de los noventa por Brasil, Argentina, Uruguay y Paraguay. Originalmente, el acuerdo fue concebido como un proceso de integración profunda, comenzando por una Zona de Libre Comercio (ZLC) y con el objetivo de largo plazo de establecer un mercado común. Sin embargo, el bloque continúa siendo una Unión Aduanera (UA) imperfecta desde finales de los noventa.

A grandes rasgos, pueden distinguirse tres etapas en el proceso de integración regional. La primera, en los años noventa, se daría en el marco de la creación formal del bloque y la profundización de diversos acuerdos institucionales; en esta etapa existió un significativo aumento de los flujos comerciales intrabloque y de la integración. La segunda, que iría de 1999 a 2002, tuvo una fuerte caída en la actividad económica y del comercio en el bloque por las profundas crisis económicas en Brasil (1999), Argentina (2001) y Uruguay (2002), y el proceso de integración no tuvo avances. Por último, en la tercera, comprendida desde 2003 hasta los años recientes, en un nuevo contexto político con gobiernos progresistas y un escenario económico mundial sumamente favorable, tuvo un nuevo impulso, aunque el mismo duró pocos años y fue de menor magnitud que el ocurrido en la primera etapa; si bien creció el comercio regional, el comercio extrazona fue el más relevante durante todo el periodo.

En general, el intercambio comercial intrabloque fue bajo, principalmente por el comportamiento de los socios mayores, ya que en los países menores fue más relevante, aunque decreciente. En promedio, para todo el periodo, la participación del comercio regional en el total fue la siguiente: Brasil, 10\%; Argentina, 27\%; Uruguay, 35\%, y Paraguay, $44 \%$. Dado el peso de Brasil, el comercio del bloque evolucionó, en nivel y tendencia, de manera bastante similar a la del socio mayor. Por lo tanto, los niveles de intercambio intrabloque fueron bajos y decrecientes, con un promedio de $16 \%$ para todo el periodo, siendo un poco mayor en las importaciones (17\% en promedio) y menor en las exportaciones ( $16 \%$ en promedio). A su vez, hubieron dos etapas diferenciadas: una de crecimiento del comercio intrarregional en los noventa y otra de caída sistemática desde fines de los noventa, llegando actualmente a niveles similares a los de principios del acuerdo. La mayoría del comercio

7 En Reig y Puchet (2018) se presenta una descripción detallada de la evolución de la integración y del comercio de los dos bloques. 
fue extrarregional, con un gran crecimiento de la participación de China en todos los países, especialmente en Brasil.

Respecto a la IED, como fue mencionado, en la década de los noventa los países liberalizaron sus regímenes de regulación y aplicaron políticas específicas de promoción con el objetivo de captar mayores flujos de inversión externa. Las medidas de liberalización, que fueron instrumentadas de forma unilateral o a través de acuerdos regionales de comercio e inversión, implicaron, entre otras, la eliminación de requisitos de desempeño, la limitación a la capacidad de los países de requerir asociaciones entre ET y empresas nacionales y cambios en la naturaleza de los mecanismos de solución de controversias sobre la IED (Chudnovsky \& López, 2006; Gallagher, López \& Porzecanski (eds.), 2008). ${ }^{8}$

Por otro lado, el TLCAN entre EEUU, Canadá y México entró en vigor en 1994 y desde sus orígenes es una ZLC, con excepciones en algunos bienes y servicios, sin el objetivo de continuar avanzando en las distintas etapas de un proceso de integración regional. En la evolución del bloque pueden distinguirse al menos dos periodos en la integración regional (Dussel Peters \& Ortíz, 2016): el primero entre 1994 y el 2000, con un fuerte dinamismo comercial, en la generación de empleo y en la IED; y un segundo periodo, iniciado en 2001, con una dinámica mucho menor en estas variables.

En este bloque, el socio mayor, EEUU, tuvo el menor nivel de comercio regional, mientras que en los otros países fue sumamente relevante pero declinante desde los 2000 respecto a los niveles iniciales. La participación del comercio regional en el total alcanzó los siguientes promedios para todo el periodo: EEUU, 29 \%; Canadá, 71 \%, y México, $71 \%$. Dado el peso de EEUU, el comercio del bloque evolucionó, en nivel y tendencia, de forma similar a la del socio mayor. En el bloque, los niveles de intercambio fueron elevados, con un promedio de $42 \%$ para todo el periodo, siendo mayor en las exportaciones ( $50 \%$ en promedio) que en las importaciones (36\% en promedio). El bloque atravesó tres etapas diferenciadas: crecimiento en los noventa, caída en los primeros años de la década del 2000 y recuperación en los años recientes. La mayor parte del comercio fue extrarregional para EEUU y el bloque, mientras que para Canadá y México fue intrarregional. Al igual que en el MERCOSUR, se destacó el gran crecimiento de la participación de China en todos los países, especialmente en EEUU.

8 Al respecto véase Bittencourt (2016) para una descripción y análisis en profundidad de las políticas aplicadas hacia el capital extranjero en los diferentes países. 
Respecto a la IED, entre las disposiciones claves del acuerdo se incluye la liberalización y protección de la IED, así como la liberalización comercial arancelaria y no arancelaria, las reglas de origen, el comercio de servicios, la protección de derechos de propiedad intelectual, la contratación gubernamental y la resolución de disputas, mientras que las disposiciones laborales y medioambientales fueron incluidas en acuerdos por separado del TLCAN (Fergusson \& Villareal, 2013).

En este contexto, es relevante considerar para el análisis de los procesos de integración la estructura de los bloques y el lugar que ocupa cada socio, en términos de su tamaño relativo. Como fue señalado en la sección 2, el tamaño de los países puede ser un factor relevante de la capacidad que éstos tienen de apropiarse de los beneficios de la integración, en especial en el caso de los países pequeños o socios relativamente menores.

Como se muestra en Reig y Puchet (2018), en el MERCOSUR Brasil es el socio mayor, seguido de Argentina, mientras que Uruguay es uno de los socios menores. En el TLCAN, EEUU es el socio mayor, Canadá es el segundo socio y México se ubica como el socio relativamente menor. En cada bloque existen grandes diferencias entre los socios y, comparando los dos bloques, existen diferencias significativas a favor del TLCAN, principalmente por las diferencias entre EEUU y Brasil. A su vez, puede caracterizarse a Uruguay y México como los socios menores o economías relativamente pequeñas dentro de sus respectivos acuerdos regionales y, además, por sus dimensiones y características, el socio menor en el MERCOSUR es un país pequeño y en el TLCAN es un país grande. En este sentido, considerando particularmente el tamaño de los bloques y países, las enormes diferencias en las magnitudes entre los bloques y los socios menores podrían generar mejores condiciones para los países del bloque del TLCAN, en términos relativos con los países del MERCOSUR, para aprovechar en mayor medida los beneficios de la integración.

A continuación se presenta evidencia sobre la evolución de la IED recibida y emitida por los países de cada bloque y los flujos según origen y destino diferenciado en intrarregional y extrarregional. ${ }^{9}$

Como se observa en la tabla 1, en los países del MERCOSUR la IED recibida creció de manera significativa durante el periodo, en especial en los años recientes (2010-2016). Brasil recibió montos elevados de IED durante todo el periodo, mientras que en Argentina la entrada de IED fue más relevante en

9 Para la descripción se consideran promedios por décadas para suavizar la gran variación que presentaron los flujos recibidos y/o emitidos de los países en algunos años del periodo analizado. 
los noventa y en los años recientes. En Uruguay también fue significativa, en particular en los años recientes, aunque mucho menor a la de los socios mayores. La IED emitida por los países aumentó (salvo en Argentina), pero en valores mucho menores a la IED recibida (columnas 3 a 5). Todos los países fueron principalmente receptores de IED (más del $80 \%$ en el promedio 19902016) (columnas 6 a 8). Brasil fue el principal receptor y emisor del bloque (más del $80 \%$ ), mientras que la participación de Argentina fue minoritaria (15\%) y la de los socios menores muy pequeña (Uruguay 2,1\%, Paraguay 0,4\%) (columnas 9 a 11). Si bien en los años noventa los socios mayores tuvieron participaciones similares, dado que Argentina recibió elevados flujos de IED, desde los 2000 Brasil pasó a dominar ampliamente la recepción (y emisión) de IED. Dado el peso de Brasil, la IED recibida y emitida en el bloque evolucionó, en nivel y tendencia, de manera bastante similar a la del socio mayor.

En la tabla 2 se presenta la IED recibida y emitida según origen y destino diferenciado en intrarregional y extrarregional. Como se aprecia, en todos los países creció la IED intra y extrarregional (columnas 4 a 6); sin embargo, mientras que en los socios mayores la IED recibida y emitida fue principalmente extrarregional, en los socios menores fue relevante la participación de la IED intrarregional. Como resultado, si bien creció la IED intrarregional durante el periodo, la misma no alcanzó valores elevados, básicamente por el comportamiento de los socios mayores, en especial de Brasil (columnas 7 a 9). En la distribución entre los países, Argentina fue el principal receptor intrarregional, seguido de Uruguay y Brasil, mientras que este último fue el principal emisor, seguido de Argentina y Uruguay (columnas 10 a 12).

En las figuras 1a y $1 \mathrm{~b}$ se presenta la IED intrarregional. Como puede apreciarse, la misma creció durante todo el periodo, en especial durante los últimos años cuando alcanzó los mayores valores. La relación bilateral más importante fue entre los socios mayores, Brasil y Argentina, que representó cerca del $60 \%$ del total de la IED del bloque. La relación bilateral de Argentina con Uruguay creció durante el periodo, alcanzando en los años recientes cerca del 30 \% del total, mientras que la de Brasil y Uruguay decreció. 


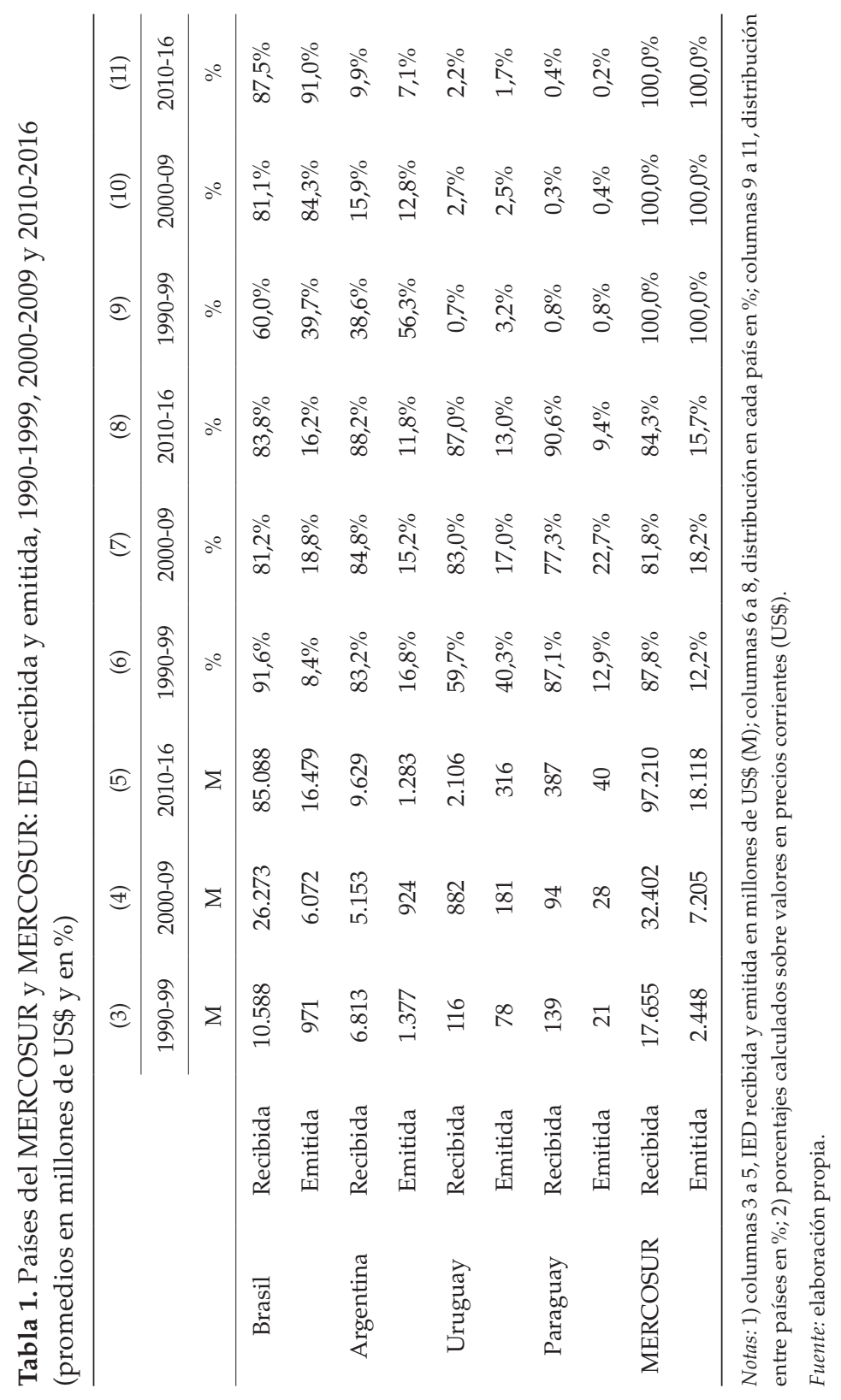




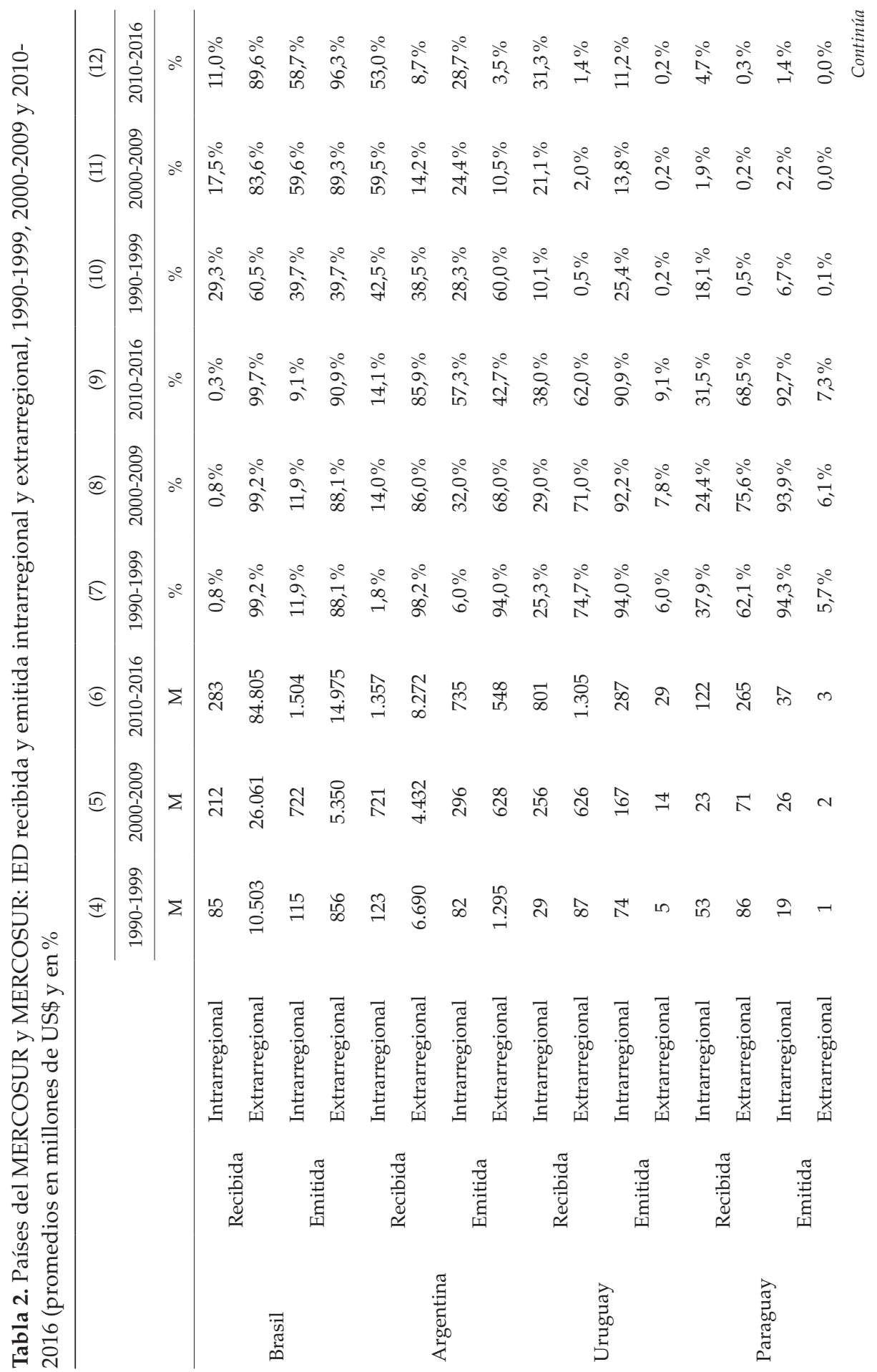




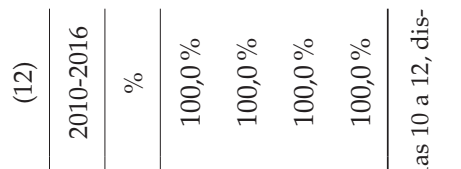

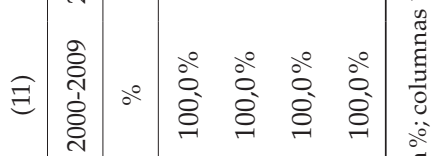

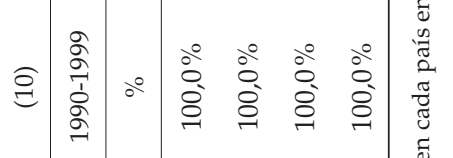

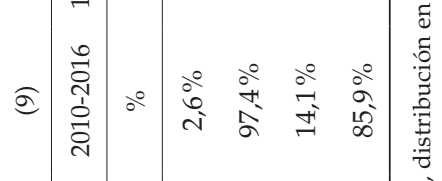

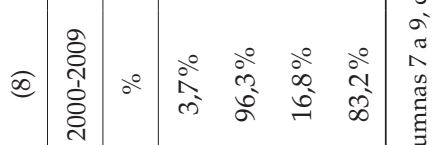

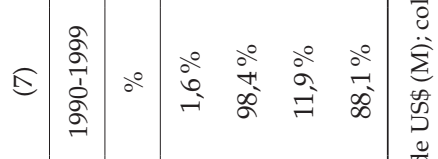

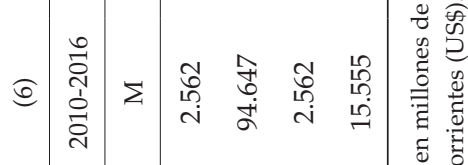

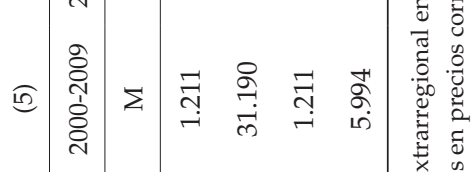

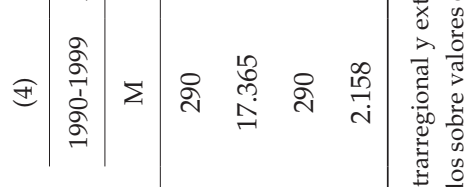

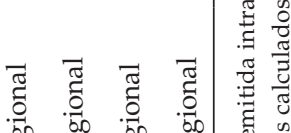

$$
\begin{aligned}
& \text { क्. }
\end{aligned}
$$

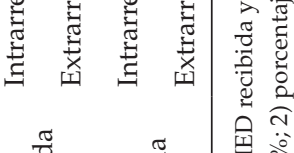

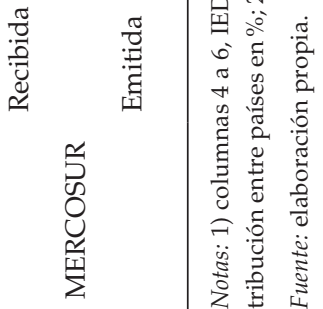



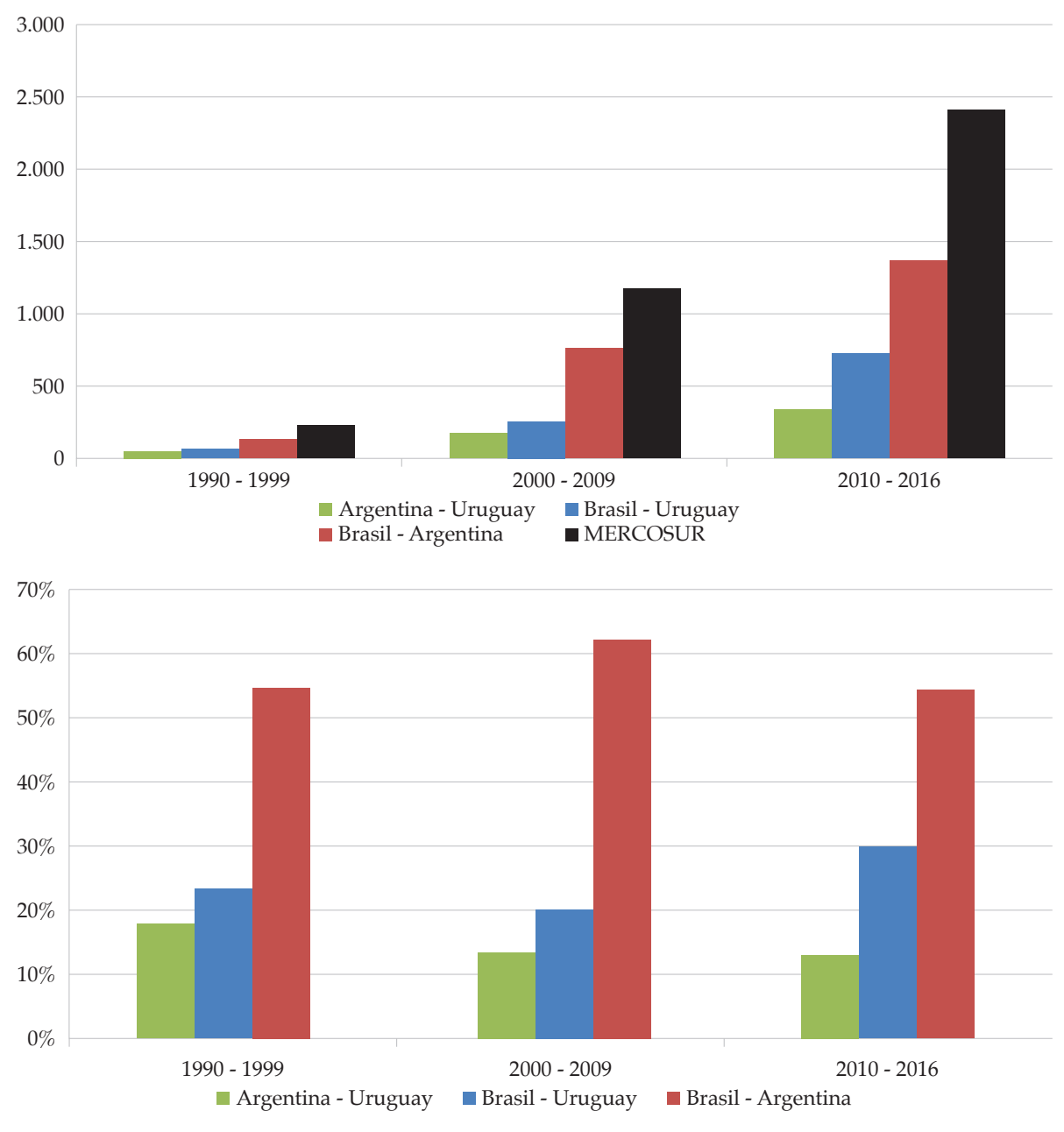

Figuras 1a y 1b. IED recibida y emitida intrarregional entre países y en el MERCOSUR, 1990-1999, 2000-2009 y 2010-2016 (promedios en millones de US\$ [panel superior] y en \% [panel inferior])

Fuente: elaboración propia.

En resumen, durante el período la IED tuvo un crecimiento significativo y los países del bloque fueron fundamentalmente receptores. La gran mayoría de la IED fue extrarregional, siendo muy baja la participación de IED intrarregional. Brasil concentró la mayoría de IED (tanto como receptor como emisor), seguido de Argentina, y muy por debajo los socios menores, Uruguay y Paraguay. Los bajos niveles de IED regional en relación con el total del 
bloque reflejaron el comportamiento de los socios mayores, especialmente de Brasil, mientras que para los socios menores fue relevante la IED regional. La IED intrarregional creció durante todo el periodo, siendo la relación bilateral más importante la de los socios mayores.

Por otro lado, en los países del TLCAN, como se observa en la tabla 3, la IED recibida y emitida tuvo un enorme crecimiento durante el periodo, alcanzando los mayores valores en los años recientes (columnas 3 a 5). En EEUU, la IED recibida y emitida tuvo una distribución similar, mientras que en Canadá la IED emitida superó levemente a la recibida. Por su parte, en México predominó la recepción de IED, aunque también fue relevante y creciente la emisión de IED (columnas 6 a 8). En la distribución entre los países, EEUU fue el principal receptor y emisor del bloque (cercano a $80 \%$ ), la participación de Canadá fue minoritaria $(15 \%)$ y la de México fue pequeña (recepción $8 \%$ y emisión $2 \%$ ) (columnas 9 a 11). Por la presencia de EEUU, la IED en el bloque evolucionó, en nivel y tendencia, de manera bastante similar a la del socio mayor.

En la tabla 4 se presenta la IED recibida y emitida según origen y destino diferenciado en intrarregional y extrarregional. Como se observa, en todos los países creció la IED tanto intra como extrarregional (columnas 4 a 6). En EEUU la gran mayoría de la IED recibida y emitida fue extrarregional (91\% y $87 \%$ en promedio $1990-2016$, respectivamente) aunque fue relevante la intrarregional ( $9 \%$ y $13 \%$ ); en Canadá fueron importantes tanto la extrarregional como la intrarregional ( $55 \%$ y $44 \%$ ), y en México predominó la intrarregional en la recepción (57\%) y la extrarregional en la emisión ( $80 \%)$. Por lo tanto, si bien en el bloque el grueso de la IED recibida y emitida fue extrarregional (en el entorno de $80 \%$ ), la IED regional creció y fue significativa (aproximadamente $20 \%$ ) (columnas 7 a 9). En la distribución entre los países, EEUU y Canadá fueron los principales receptores intrarregionales (entre $34 \%$ y $39 \%$ ), siendo un poco menor la participación de México (27\%), mientras que EEUU fue el principal emisor (57\%) seguido de Canadá (40\%) (columnas 10 a 12).

En las figuras $2 \mathrm{a}$ y $2 \mathrm{~b}$ se presenta la IED intrarregional. Como puede apreciarse, la misma creció de forma significativa durante todo el periodo, en especial entre los años 2000-2009, y en menor medida en los años recientes, cuando alcanzó los mayores valores. La relación bilateral más importante fue entre los socios mayores, EEUU y Canadá, que representó cerca del $70 \%$ del total de la IED del bloque. La relación entre EEUU y México fue relevante (aproximadamente de $25 \%$ del total), mientras que la de Canadá y México fue creciente, aunque muy baja en términos del bloque. 


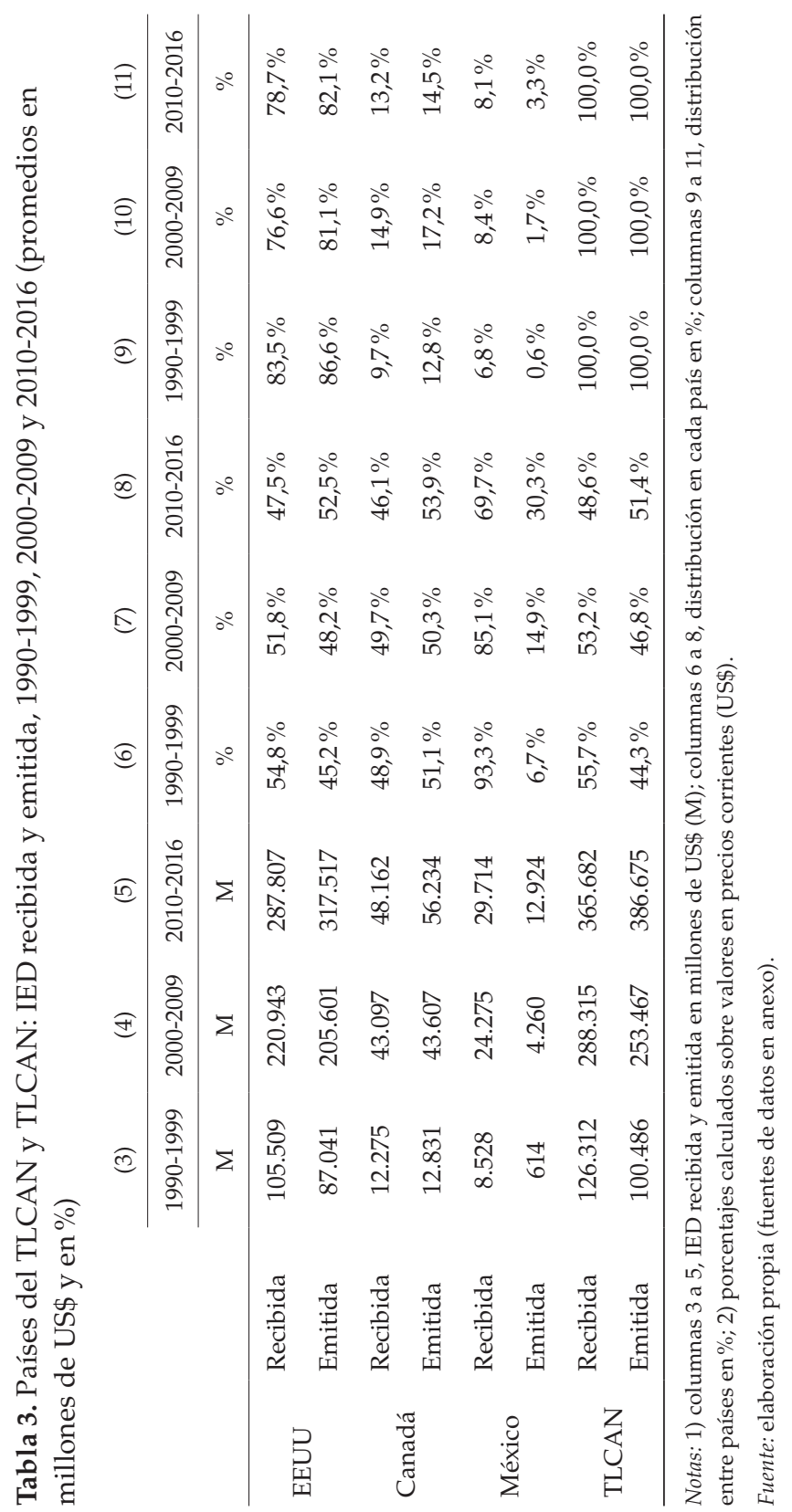




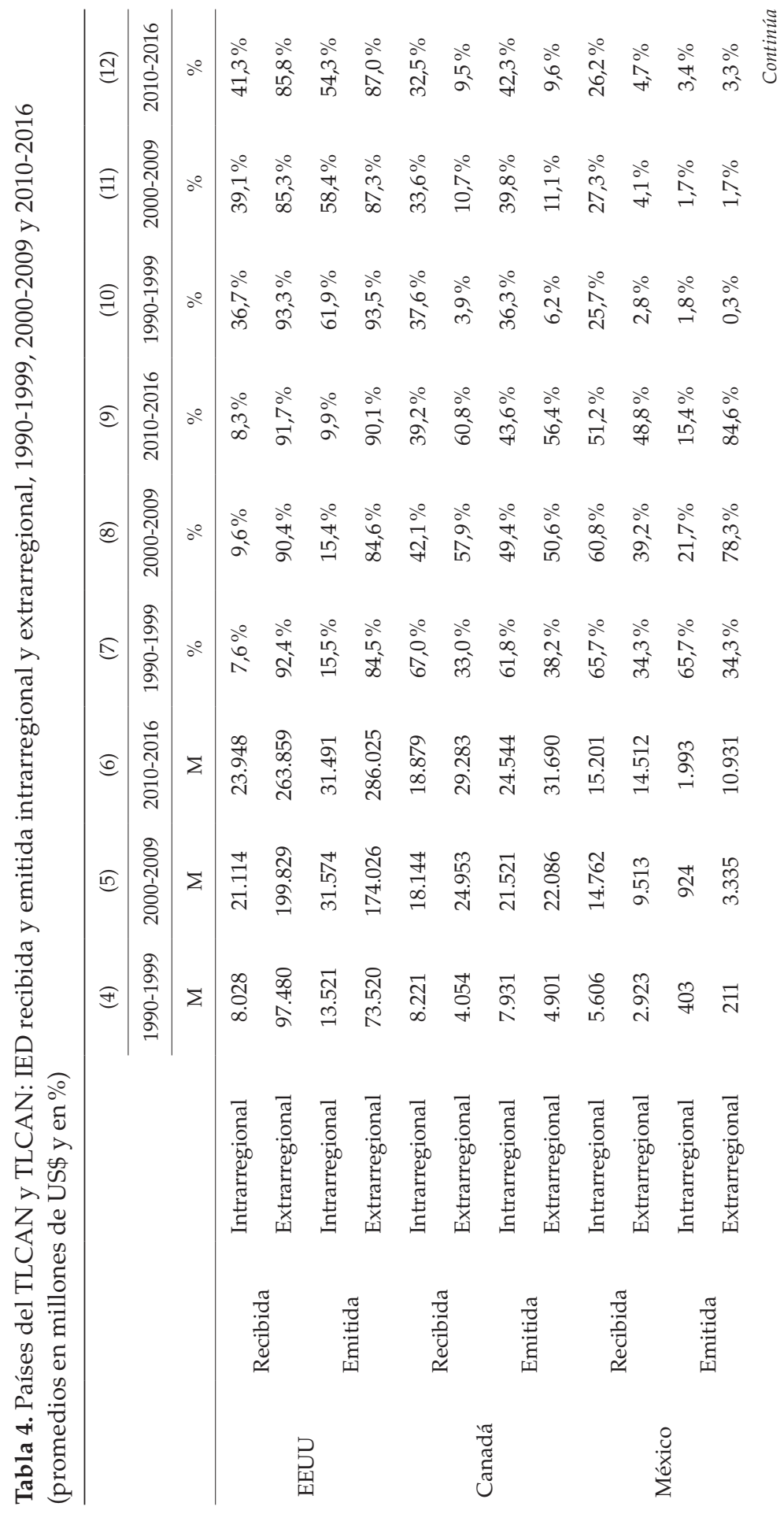




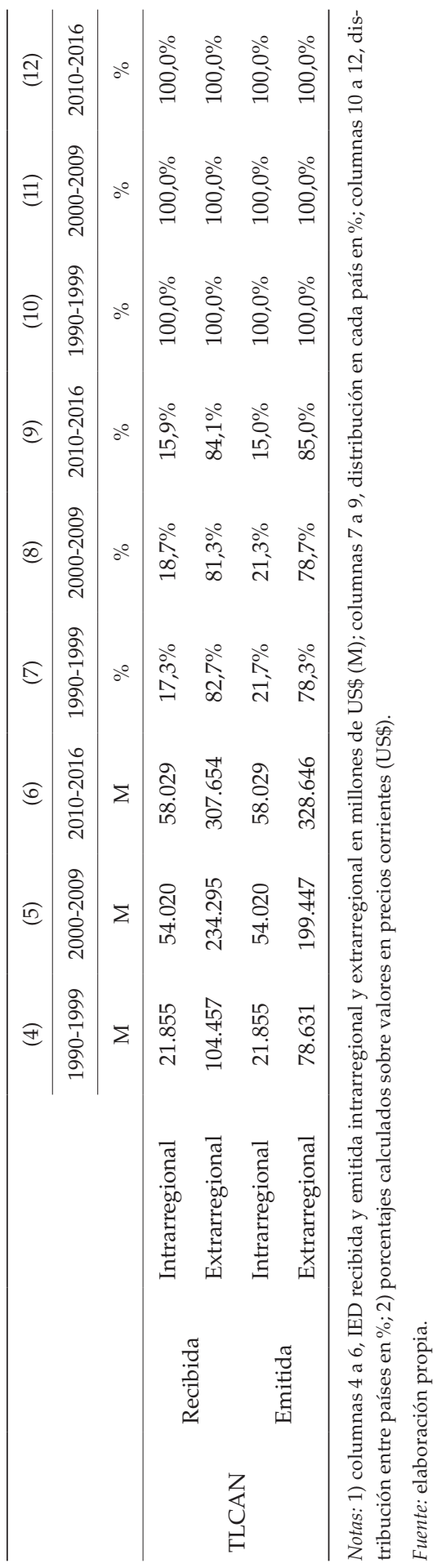



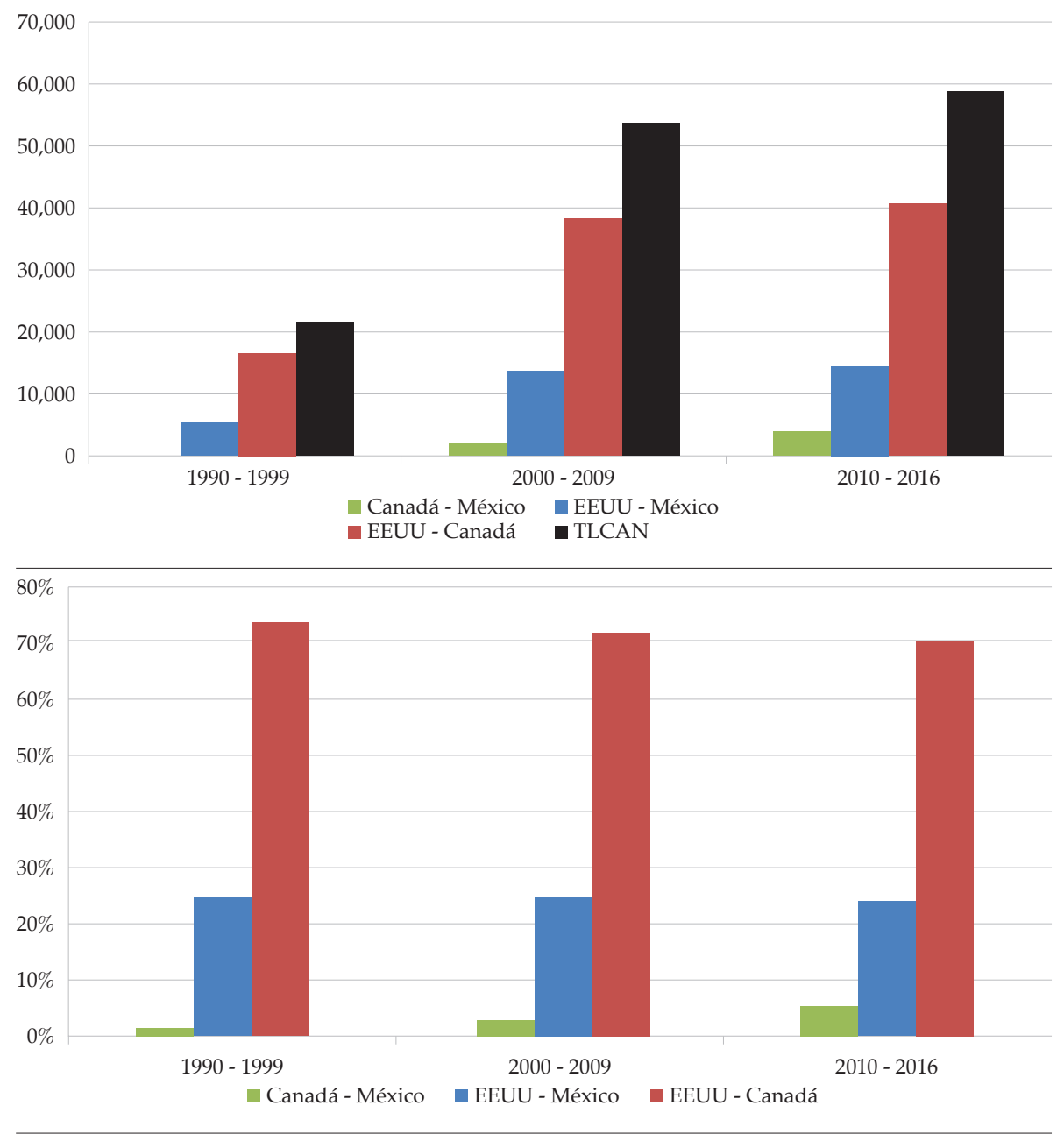

Figuras 2 a y 2 b. IED recibida y emitida intrarregional entre países y en el TLCAN, 1990-1999, 2000-2009 y 2010-2016 (promedios en millones de US\$ -panel superior- y en \% -panel inferior-)

Fuente: elaboración propia.

En resumen, durante el periodo la IED total tuvo un enorme crecimiento y los países del bloque fueron grandes receptores y emisores de IED, en especial EEUU y Canadá. La mayoría de la IED fue extrarregional, aunque fue elevada la participación de IED intrarregional. EEUU concentró la mayoría de IED (tanto como receptor como emisor), seguido de Canadá y en menor medida México. Los niveles de IED regional en el bloque reflejaron el comportamiento principalmente de EEUU, que tuvo una enorme participación en la IED y la mayoría fue extrarregional, y en menor medida de los socios 
Canadá y México, en los cuales fue muy relevante la IED regional. La IED intrarregional tuvo un fuerte crecimiento durante el periodo, en especial desde los 2000, y la relación bilateral más importante fue la de EEUU y Canadá.

\subsection{Los socios menores: Uruguay y México}

En Uruguay, los flujos recibidos tuvieron un gran crecimiento durante el periodo, alcanzando los mayores valores en los años recientes, mientras que la emisión creció aunque de forma bastante más moderada, por lo cual el país fue principalmente receptor ( $83 \%$ ) (tablas 1 y 2). A su vez, si bien la mayoría de la IED recibida fue extrarregional, la participación de la IED intrarregional fue muy relevante y creciente (34\%). En el caso de la IED emitida, el grueso fue intrarregional (91\%). A nivel del bloque, Uruguay fue el segundo receptor, después de Argentina, y el tercer emisor, después de Brasil y Argentina.

En la tabla 5 se presenta la evolución de la IED regional por países. La IED recibida creció durante todo el periodo y alcanzó los mayores valores en los años recientes. El principal origen de las inversiones fue Argentina (entre $54 \%$ y $75 \%$ ), seguido de Brasil (entre $36 \%$ y $21 \%$ ). La IED emitida también se incrementó, aunque de forma bastante más moderada que la recepción, y el principal país de destino fue Brasil (entre $41 \%$ y $58 \%$ ) y luego Argentina (entre $50 \%$ y $37 \%$ ). La participación del otro socio menor fue marginal tanto en la IED recibida como en la emitida.

Tabla 5. Uruguay: IED recibida y emitida intrarregional, 1990-1999, 2000-2009 y 2010-2016 (promedios en millones de US\$ y en \%)

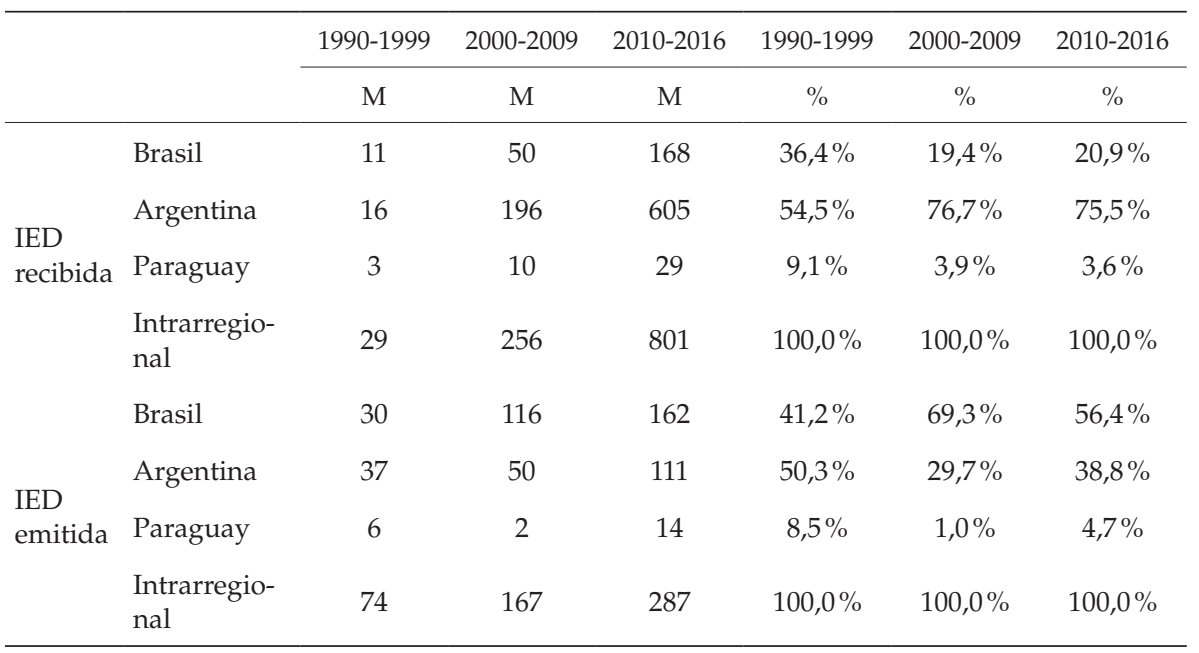

Fuente: elaboración propia. 
Por otro lado, en México los flujos recibidos tuvieron un gran crecimiento durante el periodo, alcanzando los mayores valores en los años recientes, y la emisión creció aunque de forma más moderada (tablas 3 y 4). El país fue principalmente receptor de IED (79\%); a su vez, en la IED recibida predominó la intrarregional (57\%), aunque de manera decreciente, y la emisión fue principalmente extrarregional $(80 \%)$. A nivel del bloque, tanto en la IED recibida como en la emitida, México ocupó el tercer lugar.

En la tabla 6 se presenta la evolución de la IED regional por países. La IED recibida creció durante todo el periodo, especialmente en los 2000, y alcanzó los mayores valores en los años recientes. EEUU fue el principal origen de las inversiones y su participación fue ampliamente mayoritaria (entre 95\% y $85 \%$ ) aunque decreciente. La participación de Canadá fue minoritaria (entre $5 \%$ y $15 \%$ ) y se fue incrementando en el periodo. La IED emitida también se incrementó, aunque de forma bastante más moderada que la recepción, siendo el destino principal EEUU (entre $97 \%$ y $88 \%$ ).

Tabla 6. México: IED recibida y emitida intrarregional, 1990-1999, 2000-2009 y 20102016 (promedios en millones de US\$ y en \%)

\begin{tabular}{llcccccc}
\hline & & $1990-1999$ & $2000-2009$ & $2010-2016$ & $1990-1999$ & $2000-2009$ & $2010-2016$ \\
\cline { 3 - 7 } & & $\mathrm{M}$ & $\mathrm{M}$ & $\mathrm{M}$ & $\%$ & $\%$ & $\%$ \\
\hline \multirow{2}{*}{$\begin{array}{l}\text { IED } \\
\text { recibida }\end{array}$} & EEUU & 5.313 & 13.437 & 12.849 & $94,8 \%$ & $91,0 \%$ & $84,5 \%$ \\
& Canadá & 293 & 1.325 & 2.352 & $5,2 \%$ & $9,0 \%$ & $15,5 \%$ \\
& $\begin{array}{l}\text { Intrarregio- } \\
\text { nal }\end{array}$ & 5.606 & 14.762 & 15.201 & $100,0 \%$ & $100,0 \%$ & $100,0 \%$ \\
& EEUU & 390 & 918 & 1.756 & $96,7 \%$ & $99,3 \%$ & $88,1 \%$ \\
$\begin{array}{l}\text { IED } \\
\text { emitida }\end{array}$ & Canadá & 13 & 7 & 237 & $3,3 \%$ & $0,7 \%$ & $11,9 \%$ \\
& $\begin{array}{l}\text { Intrarregio- } \\
\text { nal }\end{array}$ & 403 & 924 & 1.993 & $100,0 \%$ & $100,0 \%$ & $100,0 \%$ \\
\hline
\end{tabular}

Fuente: elaboración propia.

\section{Metodología ${ }^{10}$}

A continuación se presenta una nueva propuesta metodológica para el análisis de la integración regional, a través de los flujos de IED intrabloque entre los socios de un acuerdo. La misma es una adaptación de la metodología de análisis de la integración comercial en base a matrices de intercambio bilateral

10 Con base en los planteamientos de Puchet (2019). 
y el cálculo de índices sistémicos de integración (ISIs) definidos por Prakas, Dietzenbacher y Basu (2007). El punto de partida es la contabilización de todas las entradas y salidas de flujos de capital de los países de un acuerdo regional, a partir de los cuales se construyen matrices de flujos de fondos diferenciando los flujos emitidos y recibidos de IED. A partir de dichas matrices, es posible considerar modelos de entrada y salida por el lado de la oferta y demanda de fondos, con base en los cuales se definen y calculan los diferentes ISIs.

\subsection{Matrices de IED}

La IED es un flujo de capital que se registra contablemente en la balanza de pagos (BP) como una entrada de capital, cuando es recibido por un país $i, \mathrm{y}$ como una salida cuando es remitido por dicho país a otro. Las entradas del BP de un país son las siguientes:

$$
E_{i}=X_{i}+E_{i}^{c}+E_{i}^{k}+I E D_{i}
$$

donde $E_{i}$ es el total de las entradas provenientes del resto del mundo compuestas por las exportaciones $X_{i}$, las entradas de flujos corrientes por remuneraciones de los servicios de los factores más las transferencias $E_{i}^{c}$, las entradas de capital $E_{i}^{k}$ que comprenden movimientos de capital desde el exterior (por ejemplo nuevo endeudamiento o repatriación de capitales) y la IED recibida por el país desde el resto del mundo $I D E_{i}$. Por su parte, las salidas del balance de pagos son:

$$
S_{i}=M_{i}+S_{i}^{c}+S_{i}^{k}+I E D^{i}
$$

donde $S_{i}$ es el total de las salidas hacia el resto del mundo, compuesto por las importaciones $M_{i}$, las salidas de flujos corrientes por remuneraciones de los servicios de los factores más transferencias $S_{i}^{c}$, las salidas de capital $S_{i}^{k}$ que comprenden movimientos de capital al exterior (por ejemplo amortización de la deuda externa o salida de capitales) y la IED remitida por el país al resto del mundo IED ${ }^{i}$.

La conciliación de ambos lados del balance se realiza sumando en las salidas la variación de reservas del país $V R_{i}$; estas últimas pueden tener signo positivo si las entradas superan a las salidas o negativo en caso contrario; así se tiene: 


$$
E_{i}=S_{i}+V R_{i} o E_{i}-S_{i}=V R_{i}
$$

Desde el punto de vista conceptual, el resultado del balance es la identidad anterior. No obstante, las dificultades para identificar en la práctica todas las partidas que entran y salen de una economía hacen que esta identidad contable se satisfaga mediante un rubro adicional de errores y omisiones del balance.

La lógica del fluir de fondos de una economía abierta hace que los flujos globales de un país $i\left(F_{i}\right)$ sean iguales a la suma de los flujos internos más los externos; los flujos internos son la demanda interna $\left(D_{i}\right)$ ó el producto interno $\left(Y_{i}\right)$, mientras que los fondos externos son las entradas de fondos $\left(E_{i}\right)$ ó la salida de fondos $\left(S_{i}\right)$ más la variación de reservas $\left(V R_{i}\right)$.

Mirando los flujos globales desde la oferta de fondos o desde la demanda de fondos, se tienen las siguientes identidades:

$$
\begin{gathered}
F_{i}=D_{i}+E_{i} \\
F_{i}=Y_{i}+S_{i}+V R_{i}
\end{gathered}
$$

donde, del lado de la oferta de fondos (4) está la demanda interna $\left(D_{i}\right)$, que es equivalente a la oferta de fondos requeridos para adquirirla, más las entradas de fondos $\left(E_{i}\right)$; y del lado de la demanda de los fondos (5) está el producto interno $\left(Y_{i}\right)$, que es equivalente a la oferta de fondos internos, más las salidas de fondos $\left(S_{i}\right)$ y la variación de reservas $\left(V R_{i}\right)$.

A partir de estas identidades se plantean dos matrices que concilian los flujos de IED con las entradas y salidas de otros fondos. En particular, cada matriz representa los intercambios de estos flujos de capital que establecen entre sí los países de un bloque y hace posible analizar los vínculos establecidos entre ellos y el resto del mundo por medio de la entrada y salida de la IED.

En la tabla 7 se muestra el flujo global de fondos $\left(F_{i}\right)$ por el lado de la oferta de fondos (4), que es análoga a la tabla de comercio por el lado de la demanda (o matriz de exportaciones). En la misma se consideran las entradas del balance de pagos, en particular los flujos de IED recibidos por el país $i$ que pertenece al bloque desde los otros países miembros y el resto del mundo. Por fila registra la oferta de fondos correspondiente a la demanda interna de mercancías más los fondos externos que recibe el país $i$. 
Tabla 7. Flujo global de fondos $\left(F_{i}\right)$ por el lado de la oferta de fondos

\begin{tabular}{ccccccc}
\hline & País 1 & País 2 & $\ldots$ & País n & $E^{\prime}$ & Flujo global \\
\hline País 1 & $D_{i}$ & $I E D_{12}^{U}$ & $\ldots$ & $I E D_{1 n}^{U}$ & $E_{1}^{\prime}$ & $F_{1}$ \\
País 2 & $I E D_{21}^{U}$ & $D_{2}$ & $\ldots$ & $I E D_{2 n}^{U}$ & $E_{2}^{\prime}$ & $F_{2}$ \\
$\ldots$ & $\ldots$ & $\ldots$ & $\ldots$ & $\ldots$ & $\ldots$ & $\ldots$ \\
País n & $I E D_{n 1}^{U}$ & $I E D_{n 2}^{U}$ & $\ldots$ & $D_{n}$ & $E_{n}^{\prime}$ & $F_{n}$ \\
\hline
\end{tabular}

Fuente: elaboración propia.

donde el flujo global de fondos del país $i\left(F_{i}\right)$ que pertenece al bloque es la suma de:

i) la demanda interna $D_{i}$, que es equivalente a la oferta de fondos requeridos para adquirirla,

ii) los flujos de inversión extranjera directa $\operatorname{IED}_{i j}$ que recibe el país $i$ desde cada país $j$ del bloque,

iii) las entradas de fondos restantes $E_{i}^{\prime}$, que comprenden las exportaciones $\left(X_{i}\right)$, los ingresos corrientes por remuneraciones de los servicios factoriales más las transferencias $\left(E_{i}^{c}\right)$, y los restantes movimientos de capital desde el exterior $\left(E_{i}^{\prime k}\right)$ que incluyen la IED proveniente del resto del mundo $I E D_{i}^{R}$.

A su vez, en términos de matrices, la tabla 7 se expresa como:

$$
\left(\begin{array}{c}
F_{1} \\
F_{2} \\
\cdots \\
F_{n}
\end{array}\right)=\left[\begin{array}{cccc}
D_{1} & I E D_{12} & \cdots & I E D_{1 n} \\
I E D_{21} & D_{2} & \cdots & I E D_{2 n} \\
\cdots & \cdots & \cdots & \cdots \\
I E D_{n 1} & I E D_{n 2} & \cdots & D_{n}
\end{array}\right] l+\left(\begin{array}{c}
E_{1}^{\prime} \\
E_{2}^{\prime} \\
\cdots \\
E_{n}^{\prime}
\end{array}\right)
$$

La diferencia entre las entradas $E_{i}$ del balance de pagos y la magnitud de $E_{i}^{\prime}$ en este balance radica en que en ésta última no se incluye toda la IED que recibe el país, sino solamente la IED extrabloque o del resto del mundo $\left(I E D_{i}^{R}\right)$, ya que las entradas de capital totales $\left(E_{i}^{k}\right)$ no contienen ahora la IED proveniente del bloque, limitándose a $E_{i}^{\prime k}$.

El flujo global de fondos $\left(F_{i}\right)$ por el lado de la oferta tiene así un componente originado por la demanda interna $D_{i}$ y uno que proviene de las entradas externas: $E_{i}^{\prime}=X_{i}+E_{i}^{c}+E_{i}^{\prime K}$, tanto corrientes por demanda externa de mercancías $\left(X_{i}\right)$ y de factores que originan remuneraciones y transferencias 
sin contrapartida $\left(E_{i}^{c}\right)$, como de capital $E_{i}^{\prime k}$. Estas últimas contienen, de todas las entradas destinadas a la formación de nuevo capital: $I E D_{i}=\Sigma_{j} I E D_{i j}+I E D_{i}^{R}$, solamente aquellas provenientes del resto del mundo: $I E D_{i}^{R}$.

Los flujos de IED por cada columna $j$ son las salidas de IED que el país j envía a los otros países del bloque. En conjunto, las salidas de fondos corrientes y de capital son el reverso de las importaciones vistas como flujos de fondos hacia cada país del bloque.

Este hecho requiere introducir la matriz que muestre el flujo global de fondos por el lado de la demanda de fondos (5), la cual es análoga a la matriz de comercio por la oferta (o matriz de importaciones). En la misma se consideran las salidas del balance de pagos, en particular los flujos de IED enviados por el país $j$ que pertenece al bloque hacia los otros países miembros. Representa, por cada columna $j$, la oferta de fondos que hace el país respectivo y que demanda cada correspondiente país $i$, por lo que toda la columna sumará ahora la salida global de fondos $F_{j}$ correspondiente a la demanda de fondos que le realizan a ese país $j$. A su vez, por fila registra la demanda de fondos correspondiente al producto interno $\left(Y_{j}\right)$ más los fondos internos que emite el país $i$.

En la tabla 8 se presenta el flujo global de fondos $\left(F_{i}\right)$ por el lado de la demanda de fondos:

Tabla 8. Flujo global de fondos $\left(F_{i}\right)$ por el lado de la demanda de fondos

\begin{tabular}{ccccc}
\hline & País 1 & País 2 & $\ldots$ & País n \\
\hline País 1 & $Y_{1}$ & $I E D_{12}^{U}$ & $\ldots$ & $I E D_{1 n}^{U}$ \\
País 2 & $I E D_{21}^{U}$ & $Y_{2}$ & $\ldots$ & $I E D_{2 n}^{U}$ \\
$\ldots$ & $\ldots$ & $\ldots$ & $\ldots$ & $\ldots$ \\
País n & $I E D_{n 1}^{U}$ & $I E D_{n 2}^{U}$ & $\ldots$ & $Y_{n}$ \\
S' $^{\prime}$ & $S_{1}^{\prime}$ & $S_{2}^{\prime}$ & & $S_{n}^{\prime}$ \\
Flujo global & $F_{1}$ & $F_{2}$ & $\ldots$ & $F_{n}$ \\
\hline
\end{tabular}

Fuente: elaboración propia.

donde ahora $F_{j}$ es el flujo global de fondos del país $j$ que pertenece al bloque. Este flujo es la suma de:

i) el producto interno bruto $Y_{j}$, considerado como la oferta de fondos internos, 
ii) los flujos de inversión extranjera directa $I E D_{j i}$ desde el país $j$ hacia los otros países $i$ del bloque,

iii) las salidas de fondos restantes $S_{j}^{\prime}$, que comprenden las importaciones $\left(M_{j}\right)$, los gastos corrientes pagados por el país $j\left(S_{j}^{c}\right)$-transferencias y remuneraciones factoriales-, los movimientos restantes de capital hacia el exterior $\left(S_{j}^{\prime K}\right)$ que incluyen la IED dirigida hacia el resto del mundo por el país $j\left(I E D_{R}^{j}\right)$, y la variación de reservas $\left(V R_{j}\right)$.

A su vez, en términos de matrices, la tabla 8 se expresa como:

$$
\left(F_{1} F_{2} \ldots F_{n}\right)^{T}=l^{T}\left[\begin{array}{cccc}
Y_{1} & I E D_{12} & \cdots & I E D_{1 n} \\
I E D_{21} & Y_{2} & \cdots & I E D_{2 n} \\
\cdots & \cdots & \cdots & \cdots \\
I E D_{n 1} & I E D_{n 2} & \cdots & Y_{n}
\end{array}\right]+\left(S_{1}^{\prime} S_{2}^{\prime} \ldots S_{n}^{\prime}\right)^{T}
$$

El total de salidas de fondos del país $j$ que no comprende la IED realizada por el país $j$ en su respectivo bloque es: $S_{j}^{\prime}=M_{j}+S_{j}^{c}+S_{j}^{\prime K}+V R_{j}$. El supraíndice $T$ indica que la correspondiente matriz está transpuesta y la matriz de suma de filas es $l^{T}$.

En ambas identidades de la balanza de pagos, para que sean consistentes contablemente en un marco multipaíses, hay que restar, de las entradas de capital, la IED que cada país $i$ recibe de los otros países de su respectivo bloque y lo mismo hay que hacer con las salidas que cada país $j$ hace hacia su bloque por concepto de IED; de esta forma, se concilian las tablas multi-países.

Las matrices planteadas desde la perspectiva de la oferta y la demanda de fondos globales sólo difieren en dos aspectos: por un lado, los elementos de la diagonal principal que corresponden a la oferta y la demanda de fondos internos; y por otro, los componentes distintos de la IED intra-bloque que en un caso son las entradas restantes de capital y en el otro las salidas restantes de capital más la variación de reservas.

\subsection{Modelos de integración e indices sistémicos de integración (ISIs)}

En base a las matrices de flujo global de fondos $\left(F_{i}\right)$ por el lado de la oferta y la demanda de fondos, pueden definirse los índices sistémicos por la oferta (recepción) de IED $\left(\right.$ ISI $\left.^{\circ}\right)$, por la demanda (emisión) de IED (ISI $\left.{ }^{\mathrm{dem}}\right)$ y el global $\left(I S I^{\text {global }}\right)$, que son similares a los índices sistémicos de integración por exportaciones $\left(I S I^{e x p}\right)$, por importaciones (ISI ${ }^{\text {imp }}$ ) y el global (ISI ${ }^{\text {global }}$ ) definidos por Prakas, Dietzenbacher y Basu (2007). 
En el marco de la contabilidad de intercambio de fondos entre países de un bloque que se presentó en la sección anterior, para la derivación de los modelos de entrada y salida, así como los ISIs, se pondrá la atención focal en la IED, y para ello habrá saldos de entradas o de salidas de fondos que deben ser considerados endógenos y otros exógenos para que el modelo resultante funcione como un sistema técnicamente abierto. Una matriz de flujos de IED debe mostrar las relaciones que se establecen por medio de la inversión intra y extrabloque, lo que resulta factible si se hace una partición de las entradas y salidas exógenas al bloque en las de IED del resto del mundo y las otras entradas y salidas de fondos del resto del mundo.

Por lo tanto, serán considerados como flujos endógenos solamente las entradas y salidas de IED que reciben y emiten los países miembros del bloque, mientras que serán exógenos a cada país del bloque los fondos provenientes de transacciones corrientes de mercancías y factores, las transferencias, y las de capital, incluyendo en estas últimas también las de IED con el resto del mundo, es decir, que se considerarán flujos endógenos del sistema, los de oferta y demanda de fondos de IED que tienen lugar entre países del bloque de que se trate. En particular, serán considerados exógenos los intercambios de IED entre los países del bloque y el resto del mundo, que no están incluidos en la matriz de fluir de fondos del bloque. No obstante, así como en el caso del comercio, es probable que estos flujos sean fundamentales para entender la estructura de IED en la que está inmerso el bloque y sus países.

Por un lado, considerando la matriz del flujo global de fondos (Fi)z por el lado de la oferta de fondos (6), se definen las proporciones de IED intrabloque por origen y la demanda interna (oferta de fondos interna) respecto al flujo global de fondos:

$$
i \neq j: c_{i j}=\frac{I E D_{i j}}{F_{j}} ; i=j: c_{i i}=\frac{D_{i}}{F_{j}}, i, j=1, \ldots, n
$$

donde:

$c_{i j}$ : proporción de la IED del país $j$ a $i$ en relación al flujo global de fondos de $j$.

$c_{i i}$ : proporción de la demanda interna $(\mathrm{C}+\mathrm{I})$ del país $i$ en relación a su flujo global de fondos.

y se componen las siguientes matrices: 


$$
f=\left(\begin{array}{c}
F_{1} \\
F_{2} \\
\ldots \\
F_{n}
\end{array}\right), C=\left\{c_{i j}\right\}, e=\left(\begin{array}{c}
E_{1}^{\prime} \\
E_{2}^{\prime} \\
\cdots \\
E_{n}^{\prime}
\end{array}\right)
$$

donde:

$f$ : vector columna del flujo global de fondos de los países del bloque.

$e$ : vector columna de las entradas de capital de los países del bloque.

$C$ : matriz $n x n$ de las proporciones de IED interpaís entre los países del bloque; matriz no negativa y con sumas por columna menores que la unidad.

Sustituyendo $I E D_{i j}=c_{i j} F_{j}$ y $D_{i}=c_{i i} F_{i}$ en (6), el conjunto de ecuaciones se reescribe en su forma matricial como:

$$
f=C f+e(8), \text { ó }(I-C) f=e
$$

Estas ecuaciones definen el modelo de entrada y salida por la oferta de flujos de fondos. Las entradas son los flujos corrientes y de capital, que se consideran variables exógenas, y las salidas son el flujo global y los flujos de IED intrarregionales, variables endógenas.

El índice sistémico por la oferta de IED $\left(\right.$ ISI $\left.^{\circ}\right)$ se define de la siguiente manera:

$$
I S I^{o f}=1\left(\frac{\operatorname{det}(I-C}{\prod_{i=1}^{n}\left(1-c_{i i}\right)}\right)^{\frac{1}{n}}, 0<I S I^{o f}<1
$$

donde:

$\operatorname{det}(I-C)$ : determinante de la matriz de los flujos de IED intrarregionales en proporción al flujo global de cada país.

$\prod_{i=1}^{n}\left(1-c_{i i}\right)=\prod_{i=1}^{n} 1-\left(D_{i} / F_{i}\right)=\prod_{i=1}^{n} E_{i} / F_{i}$ : producto de la participación del total de flujos de capital en el flujo global de cada país. 
El indicador es una medida de la IED intrarregional en relación a los flujos de capital, ambas en proporción de los flujos globales de los países. Por lo tanto, a mayor IED intrarregional, es decir, a mayor integración por IED, mayor valor del ISI ${ }^{\circ \text {. }}$

Por otro lado, y de forma análoga a las definiciones y operaciones realizadas anteriormente con la matriz por el lado de la oferta de fondos, si se considera la matriz del flujo global de fondos ( Fi) por el lado de la demanda de fondos (7), se definen las proporciones de la IED intrabloque por destino y del producto interno (demanda de fondos interna) respecto al flujo global de fondos:

$$
i \neq j: d_{i j}=\frac{I E D_{i j}}{F_{j}} ; i=j: d_{i i}=\frac{Y_{i}}{F_{i}}, i, j=1, \ldots, n
$$

y se componen las siguientes matrices:

$$
f^{T}=\left(F_{1}, F_{2}, \ldots, F_{n^{\prime}}\right)^{T}, D=\left\{d_{i j}\right\}, S^{T}=\left(S_{1^{\prime}}^{\prime}, S_{2^{\prime}}^{\prime}, \ldots, S_{n^{\prime}}\right)^{T}
$$

donde la matriz $\mathrm{D}$ es una matriz no negativa y con sumas por fila menores que la unidad. Sustituyendo $I E D_{i j}=d_{i j} F_{i}$ y $Y_{i}=d_{i i} F_{i}$ en (7), el conjunto de ecuaciones se reescribe en su forma matricial como:

$$
f^{T}=D f^{T}+\mathrm{s}^{T}(11), \text { ó } f^{T}(I-D)=s^{T}
$$

Estas ecuaciones definen el modelo de entrada y salida por la demanda de flujos de fondos, donde las variables exógenas son las salidas de flujos corrientes y de capital; en este caso, para que se satisfaga la identidad del balance de pagos se suma la variación de las reservas. El índice sistémico por la demanda de IED $\left(I S I^{\mathrm{dem}}\right)$ se define de la siguiente forma:

$$
I S I^{\text {dem }}=1-\left(\frac{\operatorname{det}(I-D)}{\prod_{i=1}^{n}\left(1-d_{i i}\right)}\right)^{\frac{1}{n}}, 0<I S I^{d e m}<1
$$

Por último, se define el índice sistémico global (ISI $\left.{ }^{\text {global }}\right)$ de la siguiente manera: 


$$
I S I^{\text {global }}=1-\left(\operatorname{det}\left(1-C^{0}\right)\right)^{\frac{1}{n}}, 0<I S I^{\text {global }}<1
$$

donde la matriz $C^{0}\left(\right.$ ó $\left.D^{0}\right)$ son matrices asociadas a $C($ ó D) con diagonal nula:

$$
C^{0}=\left[\begin{array}{cccc}
0 & C_{12} & \cdots & C_{1 n} \\
C_{21} & 0 & \cdots & C_{2 n} \\
\cdots & \cdots & \cdots & \cdots \\
C_{n 1} & C_{n 2} & \cdots & 0
\end{array}\right]=\left[\begin{array}{cccc}
0 & d_{12} & \cdots & d_{1 n} \\
d_{21} & 0 & \cdots & d_{2 n} \\
\cdots & \cdots & \cdots & \cdots \\
d_{n 1} & d_{n 2} & \cdots & 0
\end{array}\right]=D^{0}
$$

De forma similar a los tres ISIs definidos para la integración comercial, los ISIs por IED varían entre 0 y 1 conforme se registra una mayor integración en el bloque.

\subsection{Socios menores en el modelo de integración}

A continuación, se describe la metodología utilizada para analizar el aporte de los socios menores al proceso de integración por IED. En primer lugar, con base en las matrices de flujos de fondos de cada bloque, el MERCOSUR con cuatro países y el TLCAN con tres países, se calculan los tres ISIs de cada uno de los bloques. En segundo, se consideran las matrices sin flujos de IED de los socios menores, es decir, la matriz del MERCOSUR con los cuatro países pero sin flujos de IED para Uruguay, y la del TLCAN con tres países y sin flujos de IED para México; en estas matrices se calculan nuevamente los tres ISIs de cada uno de los bloques, los cuales se nombran como ISIs*. Por último, se calcula la diferencia entre los ISIs obtenidos con la matriz de cada bloque y los ISIs* que surgen de la matriz sin flujos de IED de los socios menores. Esta diferencia entre los respectivos índices indica el aporte que realizan los socios menores al proceso de integración por IED en su bloque respectivo, tanto desde el punto de vista de la oferta y la demanda como a nivel global.

Por ejemplo, considerando el TLCAN y el ISI ${ }^{\text {global }}$, donde EEUU es el país 1, Canadá el país 2 y México el país 3, la matriz del bloque para calcular el índice es:

$$
I=C=\left[\begin{array}{ccc}
1 & -C_{12} & -C_{13} \\
-C_{21} & 1 & -C_{23} \\
-C_{31} & -C_{32} & 1
\end{array}\right]
$$


Si el socio menor, México, no tiene actividad de recepción o emisión de IED respecto a los otros socios, la matriz del bloque es: ${ }^{11}$

$$
I=C^{\prime}=\left[\begin{array}{ccc}
1 & -C_{12} & 0 \\
-C_{21} & 1 & 0 \\
0 & 0 & 1
\end{array}\right]
$$

\section{Resultados}

Los datos utilizados para la construcción de las matrices anuales del periodo 1990-2016 fueron los siguientes: PIB, consumo e inversión (demanda interna), exportaciones e importaciones, en US\$, con fuente Banco Mundial; las estadísticas sobre la Balanza de Pagos de los países, en US\$, con fuente FMI; las estadísticas sobre IED total y bilateral, en US\$, según diversas fuentes detalladas en el Anexo.

Los resultados de los diferentes ISIs calculados se presentan en las siguientes secciones. En primer lugar, se muestran los del MERCOSUR y el TLCAN, y en segundo los de la aplicación de la metodología para los socios menores de los dos bloques. Los mismos se presentan en promedios quinquenales para observar con más claridad las tendencias de los ISIs en el periodo, en la medida en que los mismos muestran una gran variación en algunos años puntuales. Es importante mencionar que los índices de oferta y demanda tienen mayores magnitudes respecto al global, dado que, como se presentó en la metodología y definición de los mismos, los primeros incluyen los flujos internos mientras que éstos se excluyen en el global. A su vez, la distancia en las magnitudes de los índices entre el MERCOSUR y el TLCAN es un resultado de los vínculos establecidos mediante flujos de IED por los países en los últimos 25 años, los cuales se relacionan directamente con la profundización (o no) de la integración entre los diferentes países que conforman los dos bloques.

11 En ambos casos el bloque tiene tres países, pero en el segundo el socio menor no recibe o emite IED. En ambos casos el índice tiene la misma fórmula: $I S I^{g l o b a l}=1-\left[\operatorname{det}\left(I-C^{0}\right)\right]^{1 / n}$, aunque, cuando el socio menor no recibe o emite IED, el determinante sera igual al de la matriz menor de $(2,2)$ y el exponente en la fórmula sea el mismo $(n=3)$. 


\subsection{Bloques (t4)}

Para el MERCOSUR, los bajos valores de los indicadores calculados señalan que la integración por IED fue baja, aunque tuvo una tendencia creciente en el periodo, alcanzando sus mayores niveles en 2000-2004 y 2010-2016 (Figuras 3a y 3b). Pueden distinguirse dos etapas: durante la década de los noventa,

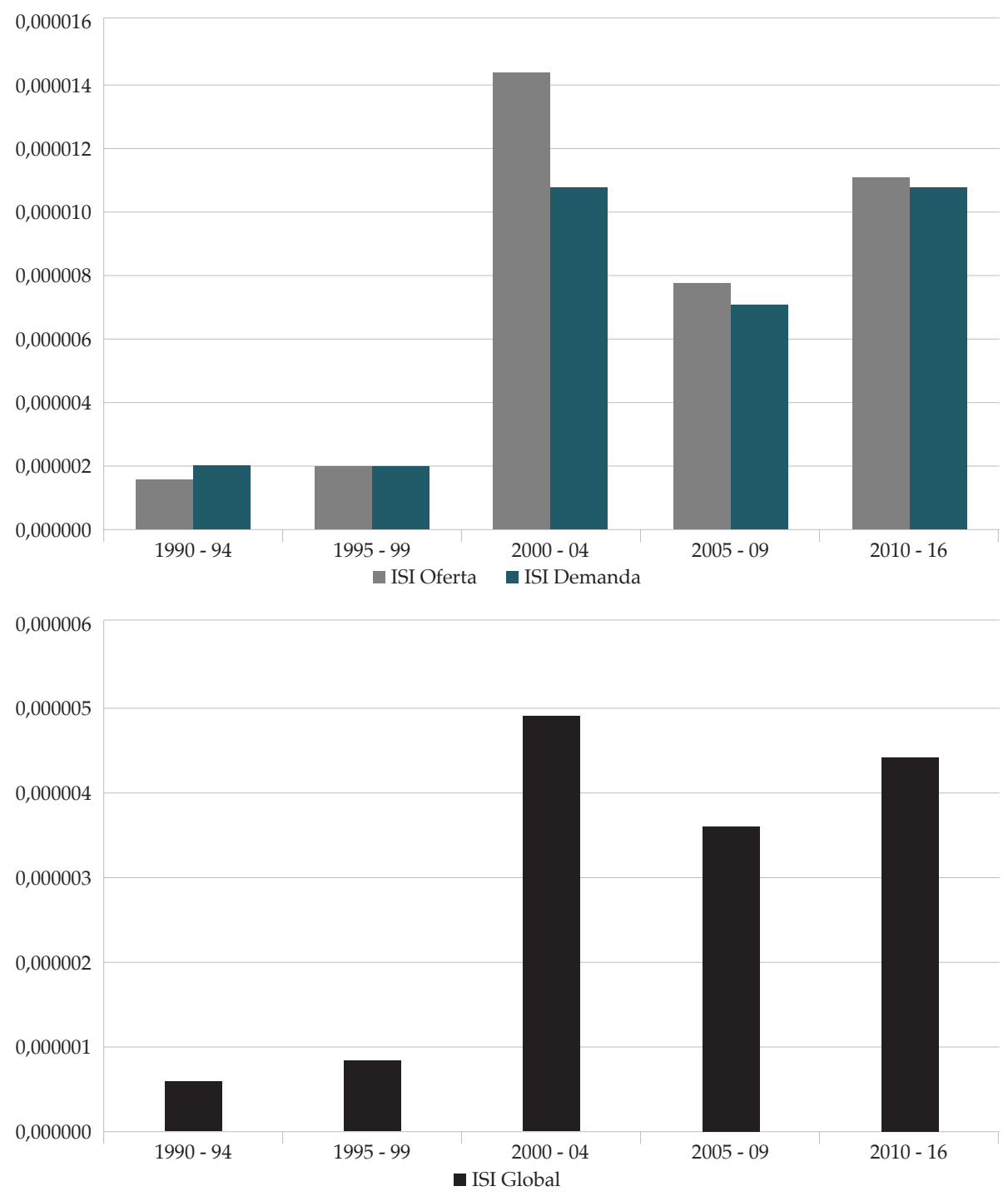

Figuras 3a y 3b. MERCOSUR: indicadores sistémicos de integración, ISI oferta y demanda (panel superior), ISI global (panel inferior)

Fuente: elaboración propia. 
el bloque presentó muy bajos niveles de integración, en la medida en que la IED intrarregional fue muy pequeña; en contraste, a partir de los 2000 creció la integración aunque con oscilaciones, dado que los flujos de inversión entre socios se incrementaron. Desde los 2000 crecieron principalmente los flujos de IED de Brasil en Argentina y, en menor medida, desde este último país a Brasil. Asimismo, los socios mayores incrementaron sus flujos de inversión en Uruguay y, en especial, en Argentina. Los niveles de integración por el lado de la oferta (recepción) de IED fueron, en general, mayores a los de la demanda (emisión).

En el TLCAN, los valores de los indicadores calculados, bastante más elevados que para el MERCOSUR, estarían señalando que la integración fue significativa, con una tendencia creciente aunque con oscilaciones (figuras 4a y 4b). Los mayores niveles de integración se alcanzaron entre 1995-1999 y 2005-2009, cuando se incrementan fuertemente las inversiones entre los socios, especialmente entre EEUU y Canadá y, en menor medida, desde EEUU a México. El bloque incrementó su integración en las décadas de los noventa y el 2000, y en los años recientes disminuyó levemente. Los niveles de integración por el lado de la oferta de IED fueron, en general, similares a los de la demanda.

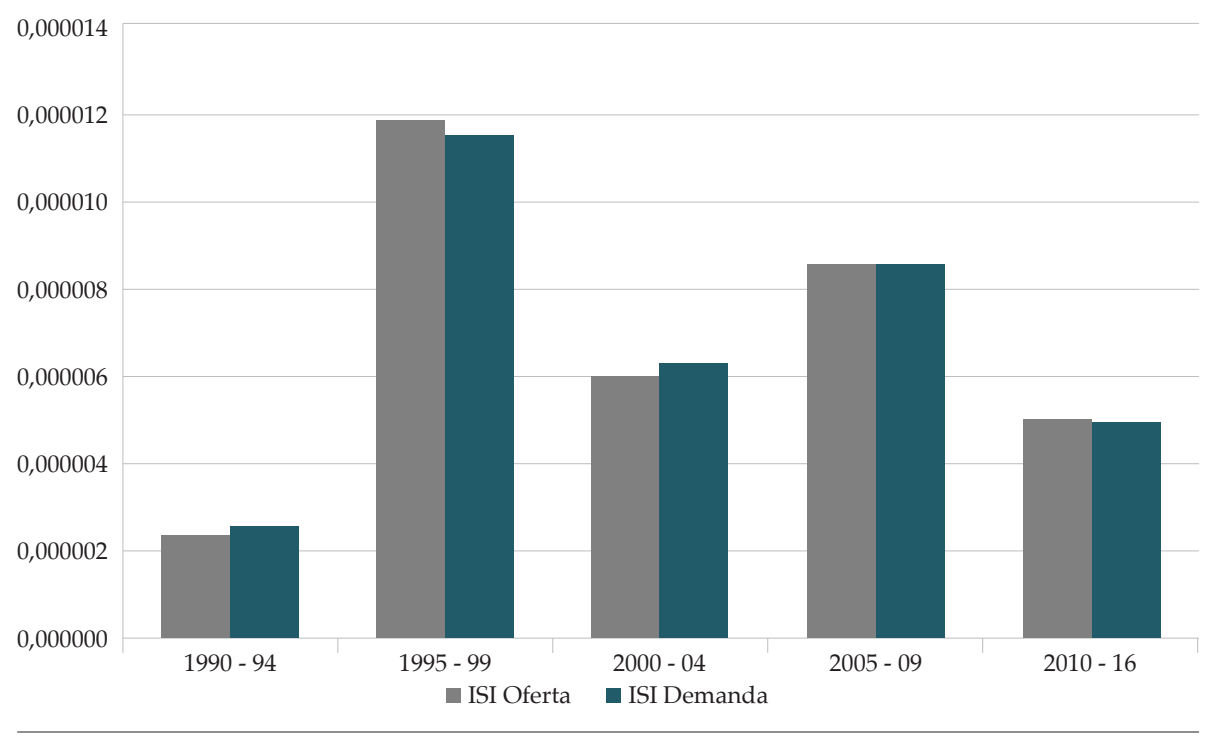




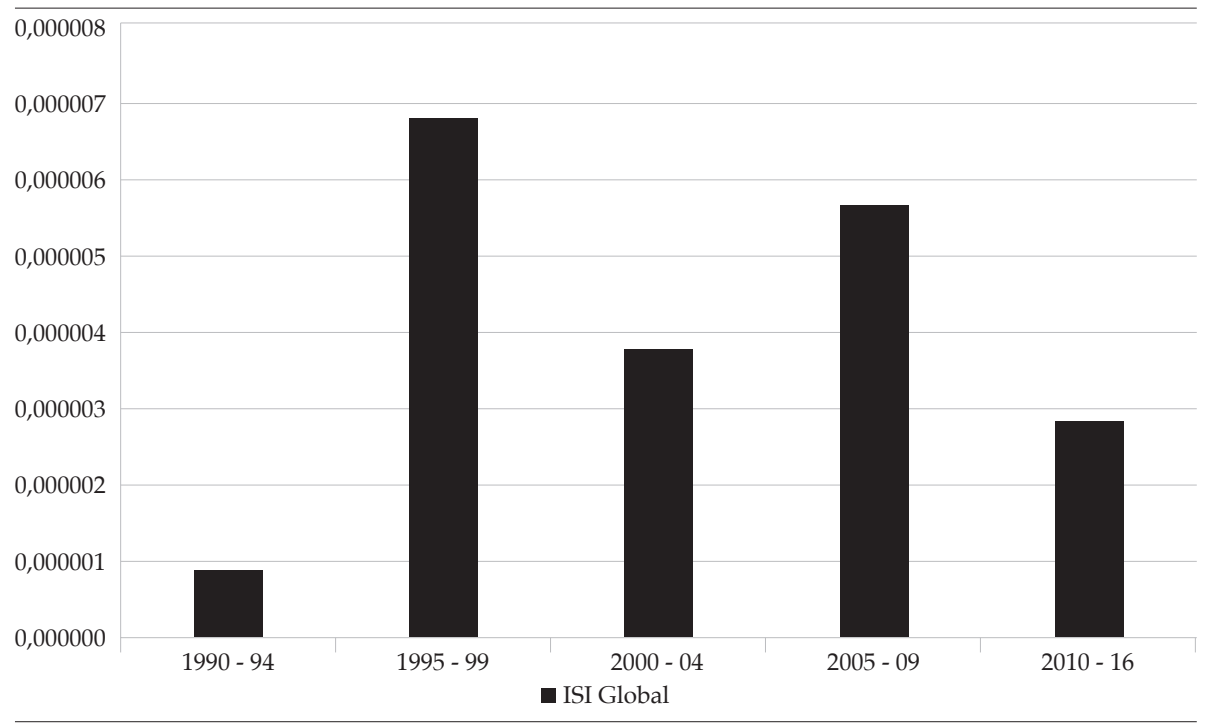

Figuras 4a y 4b. Indicadores sistémicos de integración, ISI oferta y demanda (panel superior), ISI global (panel inferior) Fuente: elaboración propia.

La integración regional por IED tuvo grandes diferencias entre los bloques, tanto en sus niveles como en su evolución. El grado de integración del TLCAN fue bastante mayor al del MERCOSUR, en el entorno de entre 8 y 13 veces para el promedio de todo el periodo, según el índice considerado: en el caso de los índices de oferta y demanda, fue superior en 9 y 10 veces respectivamente, y en el caso del índice global, en aproximadamente 13 veces.

\subsection{Socios menores: Uruguay y México}

Para Uruguay, los resultados de la aplicación de la metodología indican que su aporte al proceso de integración fue muy bajo en los noventa y creció de manera significativa en los 2000 y especialmente en los años recientes, cuando alcanzó los mayores valores (figuras $5 \mathrm{a}$ y $5 \mathrm{~b}$ ). Este incremento se asocia al crecimiento de los flujos de IED intrarregionales desde los 2000; en especial, el país recibió desde mediados de la década mayores flujos de inversión principalmente desde Argentina y, en menor medida, desde Brasil. El aporte por la oferta fue mayor al de la demanda.

En México, los resultados muestran que su aporte al proceso de integración fue alto, especialmente entre 1995-1999 y 2005-2009, cuando alcanzó los mayores valores (figuras 6a y 6b). Durante estos periodos el país recibió elevados flujos de IED, principalmente desde EEUU. En los otros periodos, si 
bien el aporte es menor, se mantiene en niveles elevados. A su vez, el aporte por la oferta fue similar al de la demanda.

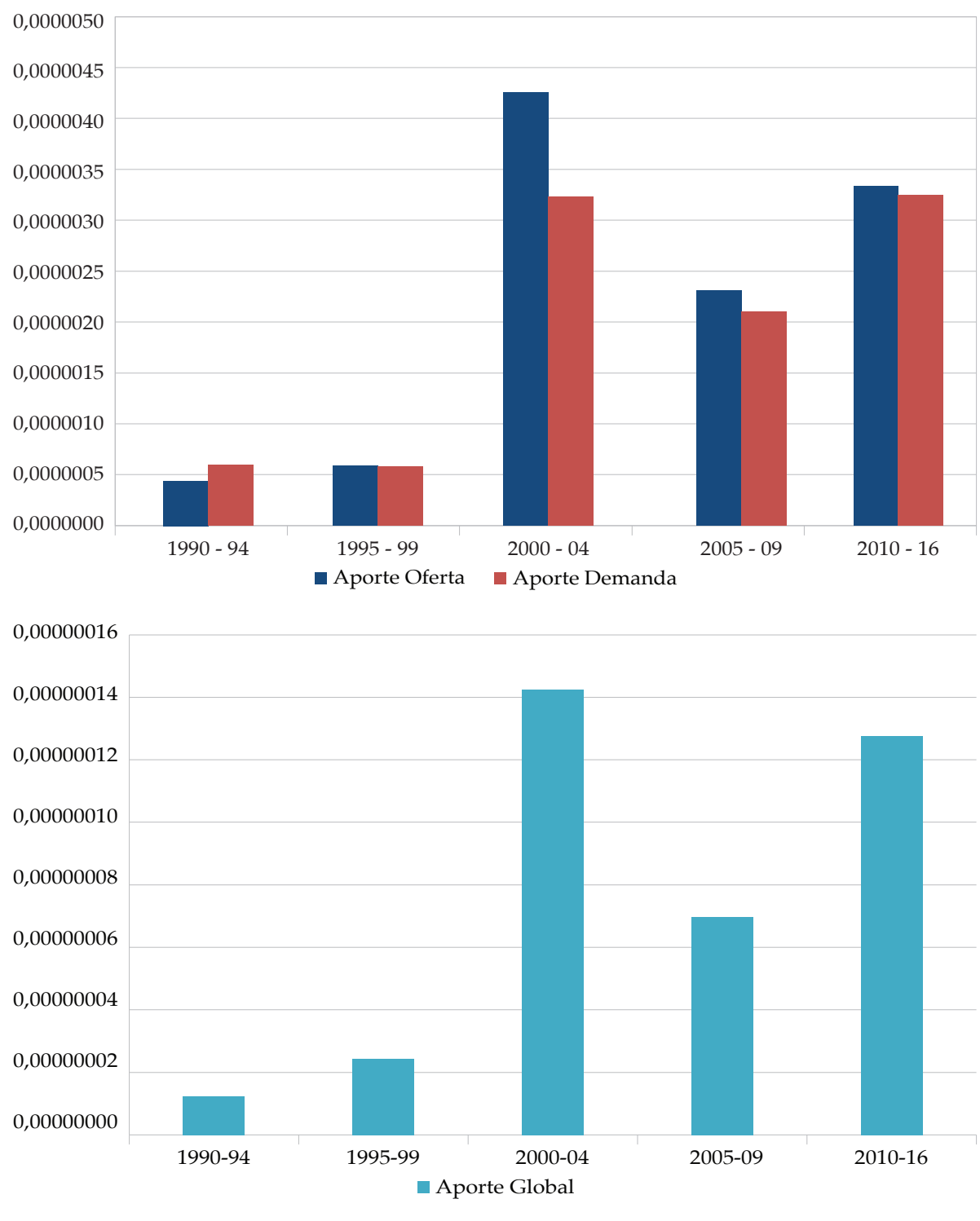

Figuras $\mathbf{5 a}$ y $\mathbf{5 b}$. Aporte de Uruguay en el MERCOSUR, aporte oferta y demanda (panel superior), aporte global (panel inferior)

Fuente: elaboración propia. 

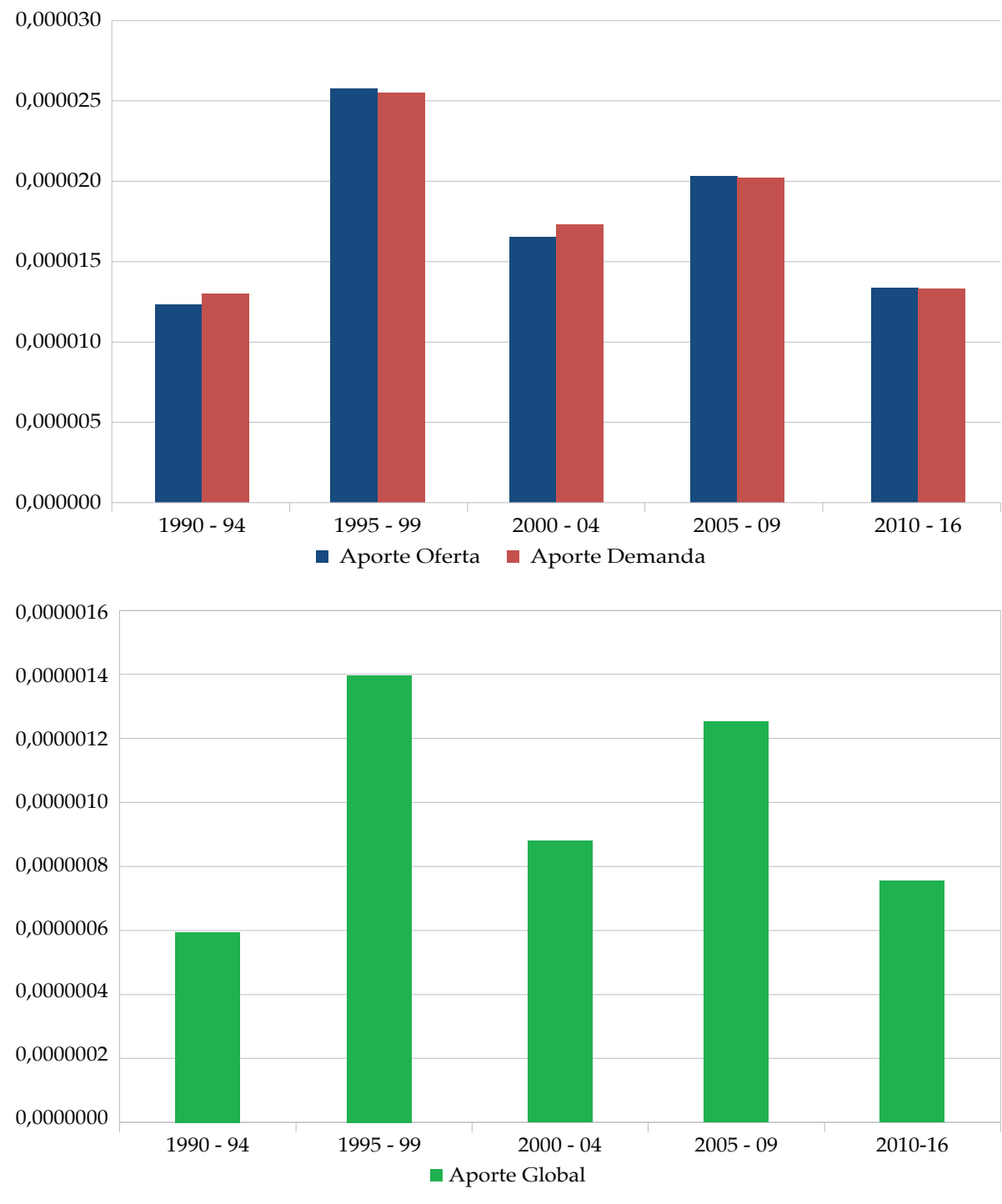

Figuras 6a y 6b. Aporte de México en el TLCAN, aporte oferta y demanda (panel superior), Aporte global (panel inferior)

Fuente: Elaboración propia

El aporte que realizó cada uno de los socios menores en su bloque a la integración por IED fue diferente, tanto en sus niveles como en su evolución. El aporte de México a la integración del TLCAN fue mayor que el de Uruguay en el MERCOSUR, en el entorno de entre 7 y 10 veces para el promedio de todo el periodo, según el índice considerado: en el caso de los índices de oferta 
y demanda, fue superior entre 7 y 8 veces respectivamente, y en el caso del índice global, en aproximadamente 10 veces.

\section{Conclusiones}

La integración por IED ha sido poco analizada hasta el presente y representa una de las dimensiones centrales de la integración regional. La misma se produce cuando empresas de un país del bloque invierten en otro país socio para establecer filiales productivas, con el objetivo de desarrollar actividades en el mercado interno y/o para conformar redes productivas y de intercambio o cadenas de producción (regionales o globales), lo que implica en ambos casos una mayor vinculación entre los países socios del acuerdo.

Como señala la evidencia empírica, los flujos de IED emitidos y recibidos por los socios a nivel regional han tenido una enorme importancia en el caso del TLCAN y, en bastante menor medida, en el MERCOSUR; en particular, los flujos de IED regionales han sido sumamente relevantes para Uruguay y México, los socios relativamente menores de cada acuerdo.

En este artículo se presenta y aplica una nueva propuesta metodológica para el análisis de la integración regional a través de los flujos de IED intrabloque entre los socios de un acuerdo, elaborada en base a la metodología de análisis estructural de la integración comercial y los índices sistémicos de integración (ISIs) definidos por Prakas, Dietzenbacher y Basu (2007). Los resultados de la aplicación de esta metodología para el análisis de los procesos de integración por IED del MERCOSUR y del TLCAN y el rol de Uruguay y México en el periodo 1990-2016, sugieren que los bloques y los socios menores tuvieron diferentes trayectorias en sus procesos de integración.

Para el MERCOSUR se encuentran pequeños valores de los indicadores, lo que estaría señalando que la integración por IED fue baja, aunque tuvo una tendencia creciente en el periodo, alcanzando sus mayores niveles entre 2000 y 2004 y el periodo 2010-2016. En contraste, en el TLCAN los valores de los indicadores calculados, bastante más elevados que para el MERCOSUR, estarían señalando que la integración por IED fue significativa, con una tendencia creciente en el periodo aunque con oscilaciones, y alcanzando los mayores niveles de integración entre 1995y1999 y 2005 y2009. Para los socios relativamente menores, en el caso de Uruguay el aporte al proceso de integración fue muy bajo en los noventa y creció de manera significativa en los 2000 y especialmente en los años recientes. En cambio, el aporte de México fue elevado en todo el período, especialmente entre 1995 y1999 y el periodo 2005-2009. 
Es relevante señalar nuevamente que la metodología del análisis estructural de carácter macroeconómico que se aplica está enfocada en los encadenamientos producidos por las relaciones entre países por medio de los flujos de IED que permite medir tanto la interdependencia entre los mismos como el papel de sus tamaños relativos. Al mismo tiempo, este planteamiento es el inicio para articular el análisis de los niveles macro y meso-económico. En este sentido, futuros trabajos profundizarán esta línea de investigación, a través de la consideración de los tipos o formas de IED predominantes entre los países y a nivel del bloque, lo cual permitirá enriquecer la explicación sobre la intensidad de la integración regional en esta dimensión.

Por último, interesa destacar que los flujos de IED intrarregionales se encuentran estrechamente vinculados a las corrientes comerciales intrabloque de los países, por lo que otra línea de investigación relevante en el futuro es la consideración en conjunto de ambas dimensiones centrales de la integración (comercio e IED) y sus relaciones, mediante la metodología de análisis estructural y los índices sistémicos de integración.

\section{Referencias}

Bittencourt, G. (2016). Políticas hacia el capital extranjero en América Latina 1990-2014. Departamento de Economía (dECON), Facultad de Ciencias Sociales (FCS), Universidad de la República (UdelaR), Uruguay. Documento de Trabajo $\mathrm{n}^{\circ} 11 / 16$.

Bittencourt, G. (coord.). (2012). América Latina frente a China como potencia económica mundial: exportaciones e inversión extranjera. Red Mercosur $n^{\circ} 20$.

Bittencourt, G., Domingo, R., \& Reig, N. (2006). IED en los países del MERCOSUR: ganadores y perdedores en los acuerdos ALCA y UE-MERCOSUR. dECON, FCS, UdelaR, Uruguay. Documento de Trabajo n ${ }^{\circ}$ 02/06.

Blomström, M., \& Kokko, A. (1997). Regional Integration and FDI. NBER Working Paper 6019.

CEPAL (2010, 2016). La Inversión Extranjera Directa en América Latina y el Caribe. CEPAL, Santiago de Chile.

Chudnovsky, D., \& López, A. (2006). Inversión extranjera directa y desarrollo: la experiencia del MERCOSUR. En J. Berlinsky, F. Pires de Souza, D. Chudnovsky, \& A. López, 15 años de MERCOSUR, Comercio, Macroeconomia e inversiones extranjeras, (pp. 347-426). Montevideo: Red de Investigaciones Económicas del Mercosur.

Chudnovsky, D., \& López, A. (coord.). (2002). Integración regional e inversión extranjera directa: el caso del MERCOSUR. Serie Red Intal, BID. 
Chudnovsky, D. (coord.) (2001). El boom de inversión extranjera directa en el MERCOSUR. Buenos Aires: Siglo XXI.

De Sousa J., \& Lochard, J. (2004). Foreign Direct Investment and Integration: Lessons for CEECs. Preliminary draft. University of Paris, France.

Dee, P., \& Gali, J. (2005): The Trade and Investment Effects of Preferential Trading Arrangements. International Trade in East Asia, NBER-East Asia Seminar on Economics, Volume 14. Cambridge: University of Chicago Press

Dussel Peters, E., \& Ortiz, S. (2016). El Tratado de Libre Comercio de América del Norte, ¿contribuye China a su integración o desintegración. En E. Dussel Peters (coord.), La nueva relación comercial entre América Latina y el Caribe-China: ¿integración o desintegración regional? (pp. 245-307). México: RED ALC-CHINA y UDUAL.

Ethier, W. (2001): The New Regionalism in the Americas: A Theoretical Framework. North American Journal of Economics and Finance, 12 (2001), 159-172.

Fergusson, I., \& Villareal, M. (2013). NAFTA at 20: Overview and Trade Effects. Cornell University ILR School, Federal Publications, Key Workplace Documents.

Gallagher, K., Porzecanski, R., \& López, A. (Eds.). (2008). Inversión extranjera directa y desarrollo sustentable. Lecciones desde las Américas. Grupo de Trabajo sobre Desarrollo y Medio Ambiente en las Américas. Tufts' Global Development and Environment Institute.

Kreinin, M., \& Plummer, M. (2008). Effects of regional integration on FDI: An empirical approach. Journal of Asian Economics, 19(AÑ), 447-454.

Marszk, A. (2014). Economic Integration and Foreign Direct Investment: Review of Main Theoretical Concepts. EBER, 2(3), 80-89.

Markusen, J.R. (2003). Multinational Firms and the Theory of International Trade. Cambridge:The MIT Press.

Prakas, D., Dietzenbacher, E., \& Basu, D. (2007). Economic Integration: Systemic Measures in an Input-Output Framework. Economic System Research, 19(4), 397-408.

Puchet, M. (en prensa). Notas metodológicas sobre comercio internacional e inversión extranjera directa en los bloques económicos, integración, apertura y crecimiento: índices sistémicos de integración y medidas de dependencia-triangularidad, interdependencia y autarquía-circularidades. dECON, FCS, UdelaR, Uruguay. De próxima publicación como Documento de Trabajo.

Reig, N. \& Puchet, M. (2018). El rol de los socios menores en la integración comercial del MERCOSUR y del TLCAN 1990-2016. dECON, FCS, UdelaR. Documento de Trabajo No 09/18. 
Trajtenberg, R. (1999). El concepto de empresa transnacional. Decon, FCS, UdelaR, Uruguay. Documento de Trabajo n $10 / 99$.

UNCTAD (2013a). Regional Integration and Foreign Direct Investment in Developing and Transition Economies. Ginebra: UNCTAD.

UNCTAD (1995, 2010, 2016). World Investment Report. Ginebra: UNCTAD.

\section{Anexo: Fuentes de información para los datos de IED total y bilateral}

1. IED total: bases de datos. Fuente principal para todos los países: UNCTAD. Otras fuentes consultadas: FMI, WDI-BM y CEPAL.

2. IED bilateral (recibida y emitida): bases de datos y publicaciones

a. Países del MERCOSUR

- $\quad$ Brasil: Balanza de Pagos de Brasil, Argentina, Paraguay y Uruguay; OCDE; UNCTAD; CEPAL; Laplane et al (2001); Chudnovsky y López (2006).

- Argentina: Balanza de Pagos de Argentina, Brasil, Paraguay y Uruguay; OCDE; UNCTAD; CEPAL; Chudnovsky y López (2001); Chudnovsky y López (2006); Bezchinsky et al. (2007); Dirección Nacional de Cuentas Internacionales (2003)

- Uruguay: Balanza de Pagos de Uruguay, Brasil, Argentina y Paraguay; OCDE; UNCTAD; CEPAL; Bittencourt y Domingo (2001); Chudnovsky y López (2006).

- Paraguay: Balanza de Pagos de Paraguay, Brasil, Argentina y Uruguay; OCDE; UNCTAD; CEPAL; Masi (2001); Chudnovsky y López (2006).

\section{Referencias de las publicaciones:}

Bezchinsky, G., Dinenzon, M., Giussani, L., Caino, O., López, B., \& Amiel, S. (2007). Inversión extranjera directa en la Argentina. Crisis, reestructuración y nuevas tendencias después de la convertibilidad. CEPAL, Documento de Proyecto $\mathrm{N}^{\mathrm{o}} 127$.

Bittencourt, G., \& Domingo, R. (2001). El caso uruguayo. En D. Chudnovsky (coord.), El boom de inversión extranjera directa en el Mercosur (pp. 255-338). Buenos Aires: Siglo XXI, Red Mercosur.

Chudnovsky, D., \& López, A. (2006). Inversión extranjera directa y desarrollo: la experiencia del MERCOSUR. En J. Berlinsky, F. Pires de Souza, D. Chudnovsky, \& A. López, 15 años de MERCOSUR, Comercio, Macroeconomia e inversiones extranjeras (pp. 347-426). Montevideo, Red de Investigaciones Económicas del Mercosur. 
Chudnovsky, D., \& López, A. (2001). El caso argentino. En D. Chudnovsky (coord.), El boom de inversión extranjera directa en el Mercosur (pp. 51-122). Buenos Aires: Siglo XXI, Red Mercosur.

Dirección Nacional de Cuentas Internacionales. (2003). La Inversión Extranjera Directa en Argentina 1992-2002. Ministerio de Economía / Instituto Nacional de Estadística y Censos.

Masi, F. (2001). El caso paraguayo. En D. Chudnovsky (coord.), El boom de inversión extranjera directa en el Mercosur. (pp. 209-253). Buenos Aires: Siglo XXI y Red Mercosur.

Laplane, M., Sarti, F., Hiratuka, C., \& Sabbatini,R. (2001). El caso brasileño. En D. Chudnovsky (coord.), El boom de inversión extranjera directa en el Mercosur (pp. 123-208). Buenos Aires: Siglo XXI, Red Mercosur.

b. Países del TLCAN

- EEUU: OCDE; UNCTAD; Secretaría de Economía, México; Balanza de Pagos, México; BEA, U.S. Department of Commerce; Statistics Canada

- Canadá: OCDE; UNCTAD; Statistics Canada, BEA, U.S. Department of Commerce; Secretaría de Economía, México; Balanza de Pagos, México

- México: OCDE, UNCTAD; Secretaría de Economía, México; Balanza de Pagos, México; BEA, U.S. Department of Commerce; Statistics Canada 
